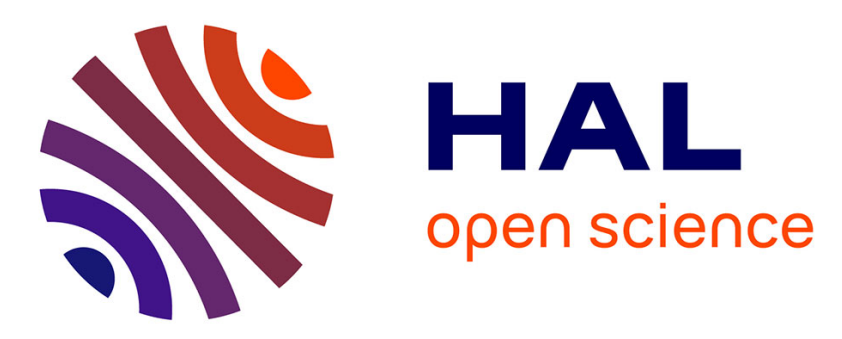

\title{
Synthesis of biobased phosphorus-containing flame retardants for epoxy thermosets comparison of additive and reactive approaches
}

Raphael Ménard, Claire Negrell, Laurent Ferry, Rodolphe Sonnier, Ghislain David

\section{To cite this version:}

Raphael Ménard, Claire Negrell, Laurent Ferry, Rodolphe Sonnier, Ghislain David. Synthesis of biobased phosphorus-containing flame retardants for epoxy thermosets comparison of additive and reactive approaches. Polymer Degradation and Stability, 2015, 120, pp.300-312. 10.1016/j.polymdegradstab.2015.07.015 . hal-01186683

\section{HAL Id: hal-01186683 \\ https://hal.science/hal-01186683}

Submitted on 4 Jun 2021

HAL is a multi-disciplinary open access archive for the deposit and dissemination of scientific research documents, whether they are published or not. The documents may come from teaching and research institutions in France or abroad, or from public or private research centers.
L'archive ouverte pluridisciplinaire HAL, est destinée au dépôt et à la diffusion de documents scientifiques de niveau recherche, publiés ou non, émanant des établissements d'enseignement et de recherche français ou étrangers, des laboratoires publics ou privés. 


\title{
Synthesis of biobased phosphorus-containing flame retardants for epoxy thermosets comparison of additive and reactive approaches
}

\author{
Raphaël Ménard $^{\mathrm{a}, \mathrm{b}}$, Claire Negrell ${ }^{\mathrm{a}}$, Laurent Ferry ${ }^{\mathrm{b}}$, Rodolphe Sonnier ${ }^{\mathrm{b}}$ * , \\ Ghislain David ${ }^{a}$ \\ a Institut Charles Gerhardt, Montpellier, UMR CNRS 5253, Equipe Ingénierie et Architectures Macromoléculaires, Ecole Nationale Supérieure de Chimie de \\ Montpellier, 8 rue de l'école normale, 34296 Montpellier Cedex 5, France \\ ${ }^{\mathrm{b}}$ Ecole des Mines d'Alès, Centre des Matériaux des Mines d'Alès - Pôle Matériaux Polymères Avancés, 6 Avenue de Clavières, 30319 Alès Cedex, France
}

\section{A B S T R A C T}

This study presents a two-steps synthesis of novel additive or reactive phosphorus-and-sulfur-containing flame retardants (P-FR) for epoxy thermosets. The first step consists in totally epoxydizing the phloroglucinol. Then, the epoxy functions grafted are partially or totally open by a thiol bearing a phosphonate group to obtain a reactive P-FR and an additive P-FR respectively. The two synthesized P-FR are then incorporated into a DGEBA-IPDA matrix according to an appropriate approach. The impact of these P-FR on glass transition temperature ( $\mathrm{Tg}$ ) is assessed by DSC. Tg values exhibit the plasticizing effect of the additive P-FR and the loss of epoxy functionality due to the incorporation of the reactive P-FR. The thermal properties of the prepared thermosets are characterized by TGA, showing the more efficient action of the reactive P-FR in condensed phase (charring). TGA-FTIR coupling show the presence of phosphorus-containing gases released during the thermal degradation but these P-containing gases have no radical scavenging action in the gas phase. PCFC analyses prove the similar flame retardant properties of the two P-FR by reducing significantly the PHRR, the THR and the EHC. The cone calorimeter tests exhibit a strong intumescent effect of the residue brought by the two P-FR, leading to insulating expanded residue.

Keywords:

Biophenol

Epoxy thermosets

Phosphorus-containing flame retardants

Reactive vs additive approaches

Intumescence

\section{Introduction}

Epoxy resins are an important part of the thermosets market and are widely used for their characteristics, such as excellent mechanical properties, adhesion or thermal resistance and they have many applications as adhesives, coatings, electronic components and materials for energy. Epoxy resins in combination with fibers are also used as matrix of composites used in sports and aeronautic industries. However, the flammability of these resins is one of their main drawbacks and requires the systematic introduction of flame retardant compounds (FR) in their formulation, allowing them to meet the fire standard.

Until recently, most of the organic flame retardants used in epoxy materials were halogenated additive systems, which present several disadvantages mainly due to the presence of halogen atoms. Indeed, beyond their intrinsically toxicity, the combustion of

\footnotetext{
* Corresponding author.

E-mail address: rodolphe.sonnier@mines-ales.fr (R. Sonnier).
}

halogenated FR produces toxics and corrosive smokes. Since 2008, new restrictions of halogenated products were imposed by REACH [1] or RoHS [2] regulations. Organophosphorus compounds are a good alternative to halogenated FR due to their combined modesof-action (charring of the condensed phase/radical scavenging in the gas phase). Moreover, their chemical structure (degree of oxidation, aliphatic/aromatic nature of the substituent groups, molecular weight ...) can be varied to fit with the polymer matrix in which they are incorporated. It is important to note that phosphorus FR release much less toxic compounds than halogenated ones.3 Currently, phosphorus-containing FR (P-FR) represent an important part of flame retardant market [4] and are currently the most studied FR systems. Our team reported [5] the synthesis of some biobased phosphorus-containing additive flame retardants by grafting phosphate functions onto hydroxyl groups of phloroglucinol. This study highlighted the potential of these compounds to improve the thermal behavior of epoxy thermosets. However, it also showed that some incompatibility issues between the additive FR and the flame-retarded matrix may be encountered, leading to 
phase segregation [5] and opacity of the material.

Moreover, the additive character of these low molecular weight FR gives them mobility in the thermoset network, that may lead to their migration to the material surface and forward to a decrease of the fire performance. A plasticizing effect of the thermoset network is also often observed [5], leading to a decrease of its mechanical properties.

In opposition to this additive approach, the reactive approach consists in covalently bonding the matrix and the FR. These bondings avoid the mobility of the FR and allow a permanent fire behavior of the epoxy thermoset. Moreover, we showed [6] that the covalent bonding prevents the phase segregation and probably the leaching. To provide this covalent bonding, different functions can be used. Indeed, the literature shows that phosphorus moieties can be brought either from epoxy monomers or from the curing agents, i.e. compounds bearing functions which are able to react with oxirane cycle, carboxylic acid, anhydride, alcohol, thiol [7] or amine. For instance, Ren et al. [8] synthesized a diepoxy phosphoruscontaining aromatic FR, Braun et al. [9] focused their study on the synthesis of phosphorus-containing diamine and used it as curing agent in epoxy resin. Xie et al. [10] carried out a two step synthesis of novel reactive phosphorus-containing curing agent, bearing a hydroxyl group and a secondary amine.

To the best of our knowledge, no biobased reactive P-FR commercially used in epoxy matrix [11,12] has been reported so far. Recently, some studies of the literature have reported the synthesis of biobased cross-linkers and epoxy monomers containing phosphorus moieties for epoxy thermosets. Gu et al. [13] synthesized phosphorus-and-nitrogen containing diol from vanillin functionalized with DOPO (9,10-dihydro-9-oxy-10-phosphaphenanthrene10-oxide). Ma et al. [14] grafted DOPO on the $\mathrm{C}=\mathrm{C}$ double bond of glycidylated itaconic acid to afford both aromaticity and phosphorus content. Lligadas et al. [15] also grafted DOPO onto glycidylated fatty acid derivatives. To favor the stability and charring of the polymer, it should be noted that the phosphorus moieties and the aromaticity are mainly brought by the DOPO, i.e. a synthetic chemical.

It is also possible to use an aromatic biobased raw material. Phenolic products coming from lignin depolymerization exhibit the required aromatic structure and are easily available. Indeed, lignins are the second most abundant raw polymer in nature and the most abundant aromatic polymer.

The action of the P-FR depends upon several parameters as the oxidation state of the phosphorus atoms [9] and in most cases the action in the condensed phase is preferred. Indeed, the amount of carbon stored in the char does not feed the combustion and reduces the heat released during the combustion, slowing the propagation of the fire. Moreover, the char formed can protect the material acting as a barrier to the heat flux and gas flow. Thus, the charring effect of the epoxy thermosets during their thermal decomposition appears as the key parameter of their flame-retardancy. The covalent bonding brought by the reactive approach could favor the charring effect. Recently, Szolnoki et al. [16] reported a study which compares the additive approach to the reactive one in epoxy thermoset using a phosphorus-containing diamine (curing agent) as reactive P-FR and the ammonium polyphosphate as additive $\mathrm{P}$ FR, showing that a lower phosphorus content is required to reach the V-0 grade at UL-94 test by the reactive approach. However, the P-FR systems used possess different chemical structures which can influence the results. Schartel et al. [17] reported a comparison between the two approaches with P-FR systems based on DOPO. The authors showed that additive P-FR volatilizes at the beginning of decomposition even if interactions between the additive and epoxy resins were also observed. On the contrary, most of the phosphorus remained in the condensed phase when it was covalently linked to the network. However, the used additive and reactive P-FR present different phosphorus-containing groups. Indeed, the synthesis of the reactive P-FR transforms the $\mathrm{P}-\mathrm{H}$ bond of the DOPO in a $\mathrm{P}-\mathrm{C}$ bond which is more thermally stable.

The present study aims to assess the influence of the covalent bonding between the FR and the matrix, comparing the additive approach to the reactive one with two biobased P-FR of comparable chemical structures, with the same phosphorus-containing groups.

Concerning the syntheses of the P-FR, both are obtained from the same biophenol, which is totally functionalized with reactive groups. Then, the reactive functions are partially or totally functionalized by a phosphorus-containing moiety, leading both to a reactive P-FR and to an additive P-FR respectively. These two P-FR are then incorporated in epoxy matrix according to the appropriate approach, i.e. additive or reactive. The flame retardant properties of the obtained thermosets are then characterized from small scale (TGA and PCFC) to bench scale test (cone calorimeter).

\section{Experimental part}

\subsection{Reagents}

Phloroglucinol, epichlorhydrin, benzyltriethylammonium chloride (TEBAC), diethylallyl phosphonate, thioacetic acid, triethylamine and acetonitrile were purchased from Sigma-Aldrich. Potassium cyanide and benzophenone were purchased from Alfa Aesar. For epoxy resins components, diglycidylether of bisphenol A (DGEBA) resin and isophorone diamine (IPDA) as curing agent were purchased from Sigma-Aldrich.

\subsection{Characterizations}

Chemical structures of the prepared compounds were determined by ${ }^{31} \mathrm{P}$ NMR, ${ }^{13} \mathrm{C}$ NMR (IG) and ${ }^{1} \mathrm{H}$ NMR spectroscopy in a Bruker Avance $400 \mathrm{MHz}$ spectrometer at room temperature in DMSO- $\mathrm{d}_{6}$ solutions. External references were tetramethylsilane (TMS) for ${ }^{1} \mathrm{H}$ NMR and ${ }^{13} \mathrm{C}$ NMR and phosphoric acid $\left(\mathrm{H}_{3} \mathrm{PO}_{4}\right)$ for ${ }^{31} \mathrm{P}$ NMR. Shifts are given in ppm.

UV irradiation was performed in a Rayonet RPR-200 UV reactor equipped with a cooling fan and 16 lamps of $35 \mathrm{~W}$ each with $\lambda_{\max }=254 \mathrm{~nm}$. Thermogravimetric analyses (TGA) were performed using a Pyris 1 TGA Perkin Elmer at a heating rate of $10^{\circ} \mathrm{C} / \mathrm{min}$ under nitrogen atmosphere. TGA-FTIR (Fourier Transformed Infrared spectroscopy) coupling was carried out using a Setaram Setsys Evolution TGA (heating rate $10^{\circ} \mathrm{C} / \mathrm{min}$, nitrogen flow $100 \mathrm{ml} /$ min) and an FTIR apparatus ThermoScientific Nicolet Is10 (resolution $0.5 \mathrm{~cm}^{-1}$, wavenumber range $400-4000 \mathrm{~cm}^{-1}$ ).

Differential Scanning Calorimetry (DSC) analyses were carried out using an NETZSCH DSC200F3 calorimeter. Constant calibration was performed using Indium, n-Octadecane and n-Octane standards. Nitrogen was used as the purge gas. The thermal properties were analyzed at $15{ }^{\circ} \mathrm{C} / \mathrm{min}$ between 20 and $200{ }^{\circ} \mathrm{C}$ to observe the glass transition temperature determined as the inflexion value in the heat capacity jump and the residual curing.

Samples were observed using an FEI Quanta 200 scanning electron microscope with the Energy Dispersive X-Ray spectroscopy (EDX) using Oxford INCA Energy 300 system and a detector of $133 \mathrm{eV}$ (at Mn). Samples were characterized after metallization in high vacuum sputtering metallizer Bal-Tec CED 030 Blatzer.

Flammability was assessed using a Pyrolysis-Combustion Flow Calorimeter (PCFC) from Fire Testing Technology (FTT UK). About $3 \mathrm{mg}$ was placed in the pyrolyzer, undergoing an increase of temperature from $20^{\circ} \mathrm{C}$ to $750{ }^{\circ} \mathrm{C}$ at $1{ }^{\circ} \mathrm{C} / \mathrm{s}$ under a nitrogen flow. Decomposition gases were sent to a combustor heated at $900{ }^{\circ} \mathrm{C}$ under air flow $\left(\mathrm{N}_{2} / \mathrm{O}_{2}=80 / 20\right)$. At this temperature and with $20 \%$ of 
oxygen, combustion was considered to be complete [18]. Heat release rate was determined by oxygen depletion according to Huggett principle [19] (1 kg of consumed oxygen corresponds to 13.1 MJ of heat released). pHRR is the maximal value of the heat release rate. The total heat released (THR) was obtained by integration of PCFC curves. The effective heat of combustion (EHC) is calculated as the ratio between THR/mass loss measured in TGA.

Thermosets fire behavior was also studied using a cone calorimeter (Fire Testing Technology) which is a powerful tool to investigate the fire behavior of polymers. A horizontal sample sheet of $100 \times 100 \times 3 \mathrm{~mm}$ was placed at $6 \mathrm{~cm}$ below a conic heater and isolated by rock wool because of the intumescent char formation observed. The samples were exposed to a $35 \mathrm{~kW} / \mathrm{m}^{2}$ heat flux in well-ventilated conditions (air rate $24 \mathrm{~L} / \mathrm{s}$ ) in the presence of a spark igniter to force the ignition. HRR was determined according to oxygen depletion (Huggett's relation) as in PCFC. This test was performed according to the ISO 5660 standard.

\section{Synthesis}

\subsection{Synthesis of triglycidyl phloroglucinol (P3EP)}

Phloroglucinol ( $3 \mathrm{~g}, 23.8 \mathrm{mmol}$ ) is solubilized in epichlorhydrin $(44 \mathrm{~g}, 0.47 \mathrm{~mol})$ with benzyltriethylammonium chloride $(0.27 \mathrm{~g}$, $1.19 .10^{-3} \mathrm{~mol}$ ) in a round bottom flask equipped with a magnetic stirrer and a condenser. The system is heated at $80{ }^{\circ} \mathrm{C}$ during $5 \mathrm{~h}$ under vigorous stirring. After reaction the excess of epichlorhydrin is distilled at $50{ }^{\circ} \mathrm{C}$ under high vacuum. The mixture is then solubilized in $80 \mathrm{ml}$ of ethyl acetate. $100 \mathrm{ml}$ of sodium hydroxide (10 $\%$ ) is then added and the biphasic system is stirred at room temperature during $30 \mathrm{~min}$. After demixing, the organic phase is washed with brine and then with water, dried on sodium sulfate, filtered and then concentrated under vacuum to obtain a yellow resin.

Yield: $68 \%$

${ }^{1} \mathbf{H}-\mathbf{N M R}\left(400 \mathrm{MHz}, \mathrm{DMSO}-\mathrm{d}_{6}, \mathrm{ppm}\right) \delta=6.19\left(3 \mathrm{H}, \mathrm{H}_{1}\right) ; 3.77$ and $4.28\left(6 \mathrm{H}, \mathrm{H}_{2}\right) ; 3.30\left(3 \mathrm{H}, \mathrm{H}_{3}\right) ; 2.69$ and $2.84\left(6 \mathrm{H}, \mathrm{H}_{4}\right)$ (Molecule 1)

\subsection{Synthesis of diethyl(3-mercaptopropyl)phosphonate (SP)}

Thioacetic acid (29.1 g, $382 \mathrm{mmol}$ ), diethylallyl phosphonate $(67.9 \mathrm{~g}, 381 \mathrm{mmol})$ and benzophenone $(0.73 \mathrm{~g}, 38 \mathrm{mmol})$ were introduced in a $660 \mathrm{ml} \mathrm{UV}$ reactor with $30 \mathrm{ml}$ of acetonitrile and a magnetic stirrer. The mixture was irradiated during $48 \mathrm{~h}$ under inert atmosphere $\left(\mathrm{N}_{2}\right)$ and vigorous stirring. The reaction was monitored by ${ }^{1} \mathrm{H}$ NMR.

After $48 \mathrm{~h}$, the resulting mixture was distillated at $80^{\circ} \mathrm{C}$ under vacuum to remove the solvent and the traces of thioacetic acid. The S-(3-(diethoxyphosphoryl)propyl) ethanethioate is obtained and then solubilized in $600 \mathrm{ml}$ of methanol with $3 \% \mathrm{~mol} /[\mathrm{S}]$ of potassium cyanid (1.24 g, $19 \mathrm{mmol})$ and a magnetic stirrer. The solution is vigorously stirred at room temperature during $24 \mathrm{~h}$. After reaction,

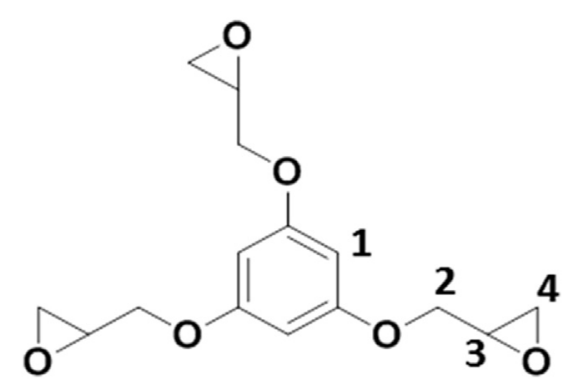

Molecule 1. Triglycidyl phloroglucinol (P3EP).

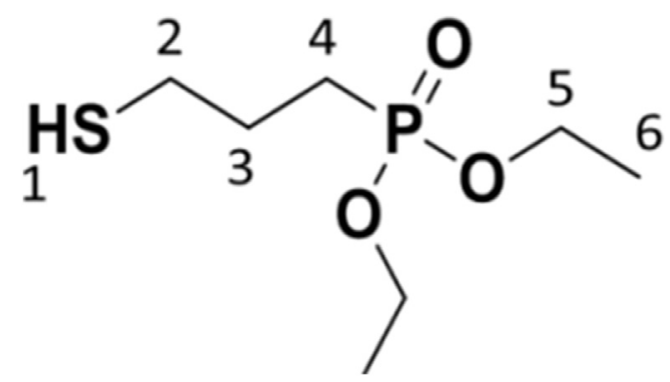

Molecule 2. Diethyl(3-mercaptopropyl)phosphonate (SP).

$100 \mathrm{ml}$ of water was added to the mixture and the product was extracted with dichloromethane. The organic phase is then dried with sodium sulfate, filtered and distilled at $60^{\circ} \mathrm{C}$ under vacuum. The diethyl(3-mercaptopropyl)phosphonate is obtained. Yield: $82 \%$

${ }^{31} \mathrm{P}$ NMR (162 MHz, $\left.\delta, \mathrm{ppm}\right): 31.7$.

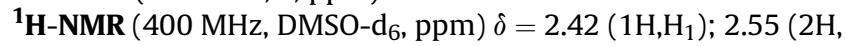
$\left.\mathrm{H}_{2}\right) ; 1.81\left(4 \mathrm{H}, \mathrm{H}_{3}\right.$ and $\left.\mathrm{H}_{4}\right) ; 3.96\left(4 \mathrm{H}, \mathrm{H}_{5}\right) ; 1.23\left(6 \mathrm{H}, \mathrm{H}_{6}\right)$ (Molecule 2$)$.

\subsection{Synthesis of Diglycicyl thiophosphonate phloroglucinol (P2EP1SP)}

Triglycidyl phloroglucinol (26.15 g, $89 \mathrm{mmol})$ is introduced in a $250 \mathrm{ml}$ two-necked round bottom flask equipped with a mechanical stirrer at $50{ }^{\circ} \mathrm{C}$. Diethyl(3-mercaptopropyl)phosphonate $(18.85 \mathrm{~g}, 0.089 \mathrm{~mol})$ is first mixed with $5 \% \mathrm{~mol}$ of triethylamine $(0.45 \mathrm{~g}, 4.45 \mathrm{mmol})$. Then, this mixture is introduced slowly in the round bottom flask under inert atmosphere. The system is heated at $50{ }^{\circ} \mathrm{C}$ during $5 \mathrm{~h}$ under vigorous stirring. After reaction, the system is solubilized in $150 \mathrm{ml}$ of ethyl acetate and then extracted with water. The organic phase is dried with sodium sulfate, filtered and then evaporated under vacuum. Yield $=87 \%$

${ }^{31}$ P-NMR (162 MHz, DMSO-d 6 , ppm): 31.5.

${ }^{1} \mathbf{H}-\mathrm{NMR}$ (400 MHz, DMSO-d 6 , ppm) $\delta=2.68$ and $2.83\left(4 \mathrm{H}_{1} \mathrm{H}_{1}\right)$; $3.30\left(2 \mathrm{H}, \mathrm{H}_{2}\right)$; 3.76 and $4.27\left(4 \mathrm{H}, \mathrm{H}_{3}\right) ; 6.16\left(3 \mathrm{H}, \mathrm{H}_{4}\right) ; 3.92\left(2 \mathrm{H}, \mathrm{H}_{5}\right)$; $5.21\left(1 \mathrm{H}, \mathrm{H}_{6}\right), 2.74\left(2 \mathrm{H}, \mathrm{H}_{7}\right) ; 2.62\left(2 \mathrm{H}, \mathrm{H}_{8}\right)$; from 1.67 to $1.86\left(4 \mathrm{H}, \mathrm{H}_{9}\right.$ and $\left.\mathrm{H}_{10}\right) ; 3.98\left(4 \mathrm{H}, \mathrm{H}_{11}\right) ; 1.22\left(6 \mathrm{H}, \mathrm{H}_{12}\right)$ (Molecule 3$)$

\subsection{Synthesis of tri-thiophosphonated phloroglucinol (P3SP)}

Triglycidyl phloroglucinol $(20.0 \mathrm{~g}, 0.068 \mathrm{~mol})$ is introduced in a $250 \mathrm{ml}$ two-necked round bottom flask equipped with a mechanical stirrer at $50{ }^{\circ} \mathrm{C}$. Diethyl(3-mercaptopropyl)phosphonate (44.52, $0.21 \mathrm{~mol})$ is first mixed with $5 \% \mathrm{~mol}$ of triethylamine $(1.06 \mathrm{~g}$, $10.5 \mathrm{mmol})$. Then, this mixture is introduced slowly in the round bottom flask under inert atmosphere. The system is heated at $50{ }^{\circ} \mathrm{C}$ during $5 \mathrm{~h}$ under vigorous stirring. After reaction, the system is

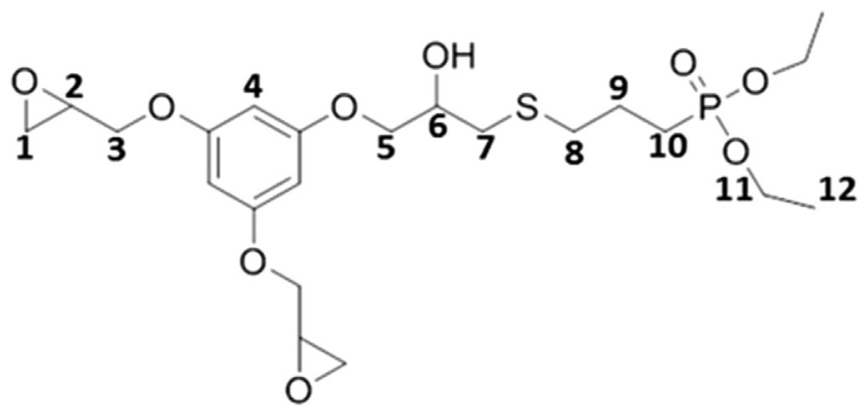

Molecule 3. Diglycicyl thiophosphonate phloroglucinol (P2EP1SP). 


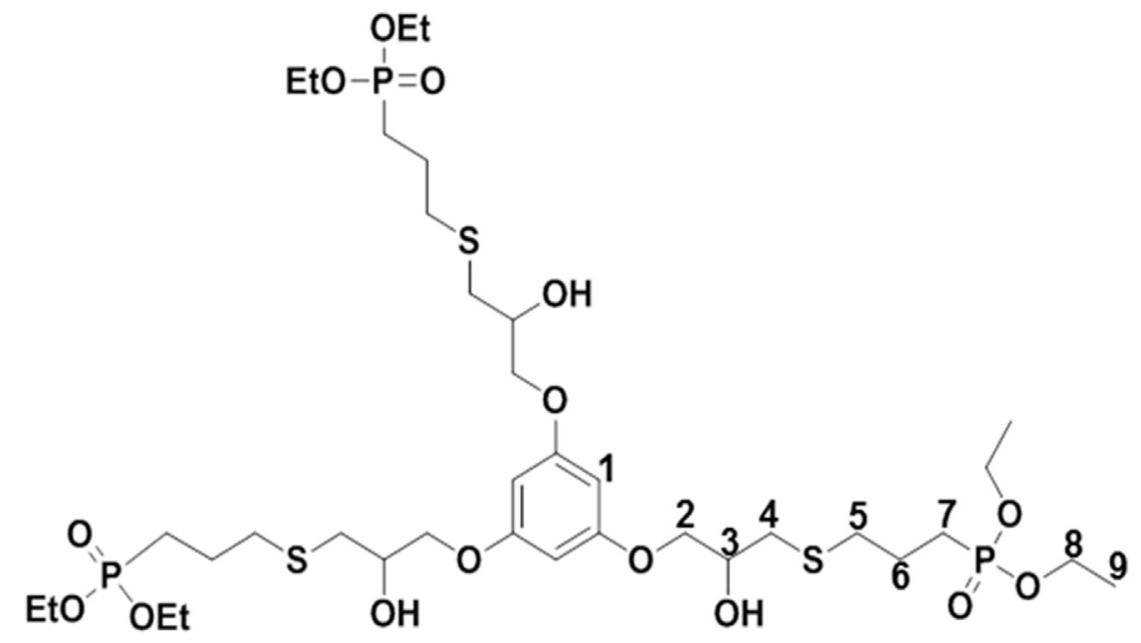

Molecule 4. Tri-thiophosphonated phloroglucinol (P3SP).

solubilized in $150 \mathrm{ml}$ of ethyl acetate and then extracted with water. The organic phase is dried with sodium sulfate, filtered and then evaporated under vacuum. Yield $=82 \%$

${ }^{31}$ P-NMR (162 MHz, DMSO-d 6, ppm): 31.5.

${ }^{1}$ H-NMR (400 MHz, DMSO-d 6 , ppm) $6.16\left(3 \mathrm{H}, \mathrm{H}_{1}\right) ; 3.92\left(6 \mathrm{H}, \mathrm{H}_{2}\right)$; $5.21\left(3 \mathrm{H}, \mathrm{H}_{3}\right) ; 2.74\left(6 \mathrm{H}, \mathrm{H}_{4}\right) ; 2.62\left(6 \mathrm{H}, \mathrm{H}_{5}\right)$; from 1.67 to $1.86\left(12 \mathrm{H}, \mathrm{H}_{6}\right.$ and $\left.\mathrm{H}_{7}\right) ; 3.98\left(12 \mathrm{H}_{1} \mathrm{H}_{8}\right) ; 1.22\left(18 \mathrm{H}, \mathrm{H}_{9}\right)$ (Molecule 4$)$

\subsection{Thermosets preparation}

Different thermosets were prepared with the different FR synthesized to evaluate the influence of FR content and thus of the phosphorus content brought by the two approaches on the flame retardancy. The FR was solubilized in epoxy monomer under stirring at $80^{\circ} \mathrm{C}$ for $10 \mathrm{~min}$. The mixture was cooled at $50{ }^{\circ} \mathrm{C}$ to avoid any crosslinking upon mixing with the hardener. A stoichiometric epoxy/amine ratio (2/1) was used. The system was stirred manually for $5 \mathrm{~min}$. Lastly the mixture was crosslinked in a circular rubber mold according to the following temperature program: $4 \mathrm{~h}$ at $80^{\circ} \mathrm{C}$ and $10 \mathrm{~h}$ at $150{ }^{\circ} \mathrm{C}$. Thermosets were named according to their phosphorus content followed by the used monomers: "X\%P(FR used)". Table 1 summarizes the weight composition of the prepared thermosets.

\section{Results and discussion}

This study aims at assessing the influence of the covalent bonding brought by the reactive approach on the flame retardant properties of the P-FR. To observe the influence of this parameter, it is necessary to use similar chemical structures for both the additive P-FR and the reactive P-FR. Concerning their syntheses, both P-FR derive from the same reagents (Scheme 1). Phloroglucinol is chosen as biobased resource. Indeed, the phloroglucinol shows a symmetrical structure, which allows the three hydroxy functions to have the same reactivity. Our strategy consists first in epoxydizing phloroglucinol by reaction of epichlorhydrin with hydroxy groups.

The phosphorus-containing precursor chosen is a thiol for their excellent reactivity with the oxirane cycles. Thus, in a second step, a phosphorus-containing thiol will be reacted with epoxy groups. The stoichiometry between thiol and epoxy will be varied from 1:3 to $3: 3$ to obtain either additive P-FR, named P3SP, or reactive P-FR, named P2EP1SP. The influence of the sulfur content is not studied in this paper. To promote the charring effect in both cases, we have chosen the phosphonate groups as phosphorus moieties.

\subsection{Synthesis of triglycidyl phloroglucinol (P3EP)}

Glycidylation of phloroglucinol was based on the method developed by Aouf et al. [20], which consists firstly in solubilizing the biophenol in a large excess of epichlorhydrin in presence of an ammonium base. Then, the obtained product was treated with sodium hydroxide solution to close the opened oxirane rings.

The ${ }^{1} \mathrm{H}$ NMR spectrum of the final product (S.I.1) allows determining its epoxy functionality, by comparing the integration of the signal of the aromatic protons at $6.19 \mathrm{ppm}$ to the integration of the signal corresponding to the proton on the tertiary carbon of the glycigyl group at $3.30 \mathrm{ppm}$. The final epoxy functionality of P3EP was determined equal to 2.6 epoxy functions/aromatic ring. The P3EP was totally functionalized with epichlorhydrin, but some side reactions (not detailed in this paper) reduce the final epoxy functionality of the P3EP compound.

\subsection{Synthesis of diethyl(3-mercaptopropyl)phosphonate (SP)}

The sulfur-and-phosphorus-containing flame retardants are expected to show a strong potential for synergistic effect between

Table 1

Compositions of the formulated epoxy thermosets.

\begin{tabular}{|c|c|c|c|c|c|}
\hline & Epoxy monomer $(\mathrm{w} \%)$ & Curing agent $(\mathrm{w} \%)$ & P-FR $(w \%)$ & Phosphorus content ( $w \% \mathrm{P} /$ thermoset) & Average epoxy functionality of the epoxy monomers \\
\hline reference & DGEBA (80.0) & IPDA (20.0) & none & 0 & 2.0 \\
\hline \multirow[t]{3}{*}{ Additive approach } & DGEBA (72.0) & IPDA (18.0) & P3SP (10.0) & 1 & 2.0 \\
\hline & DGEBA (63.8) & IPDA (16.0) & P3SP (20.2) & 2 & 2.0 \\
\hline & DGEBA (55.8) & IPDA (14.0) & P3SP (30.2) & 3 & 2.0 \\
\hline \multirow[t]{3}{*}{ Reactive approach } & DGEBA (64.6) & IPDA (18.7) & P2EP1SP (16.7) & 1 & 1.97 \\
\hline & DGEBA (49.5) & IPDA (17.4) & P2EP1SP (33.1) & 2 & 1.94 \\
\hline & DGEBA $(34.4)$ & IPDA (16.1) & P2EP1SP (49.5) & 3 & 1.90 \\
\hline
\end{tabular}


Table 2

Weight composition of the cone calorimeter residues from SEM-EDX.

\begin{tabular}{lllll}
\hline Thermosets & w\%C & w\%O & w\%P & w\%S \\
\hline DGEBA-IPDA & 79.8 & 20.2 & $\mathrm{X}$ & $\mathrm{X}$ \\
3\%P-P3SP & 69.1 & 22.1 & 8.2 & 0.65 \\
3\%P-P2EP1SP & 63.4 & 26.6 & 9.4 & 0.78 \\
\hline
\end{tabular}

the sulfur and phosphorus atoms, which may improve the flame retardant performances. Dai et al. [21] reported the efficiency of a sulfoxide and phosphate containing compound on polyester thermoset. Expecting the same effect in an epoxy thermoset, a thiol bearing a phosphonate group was used to partially or totally functionalize the epoxy functions of the P3EP. However, since the sulfur content is systematically equals to the phosphorus one, its effect will not be studied in this paper. Indeed, thanks to their high reactivity, thiol compounds can react either by radical or by nucleophilic route. The thiol-epoxy reaction, which is often considered as click reaction [22-25], was used to graft a phosphonate group on P3EP structure. However, to the best of our knowledge, no thiol bearing phosphonate function is commercially available so far. Thus prior to this reaction, the synthesis of a thiol bearing a phosphonate group was required.

Boutevin et al. has already reported [26] a two-steps synthesis under mild conditions of the diethyl(3-mercaptopropyl)phosphonate (SP) (Scheme 2). The SP structure presents only three $\mathrm{CH}_{2}$ groups as spacer between the sulfur and phosphorus atoms, which may be suitable to limit the potential fuels for flame retardant applications. The synthesis of SP is described on S.I.3.
4.3. Synthesis of diglycidyl thiophosphonated phloroglucinol (P2EP1SP) and trithiophosphonated phloroglucinol (P3SP)

The thiol-phosphonate (SP) was then used to either partially or totally functionalize the epoxy functions of the P3EP by a nucleophilic addition, leading to the reactive P2EP1SP and to the additive P3SP respectively. The thiol SP was firstly mixed with a catalytic amount of base (5\% mol of triethylamine) in order to partially form the thiolate ion and then added to the P3EP at $50{ }^{\circ} \mathrm{C}$. From a thio1 :epoxy ratio of $1: 3$, the P2EP1SP was obtained and was characterized by ${ }^{1} \mathrm{H},{ }^{13} \mathrm{C}$ and) HMBC-2D (Heteronuclear Multi Quantum Correlation NMR (Fig. 1). The obtained 2D spectrum confirmed the covalent grafting by the presence of a correlation spot between the terminal carbon of P3EP $\left(C_{h}\right)$ and the protons on the carbon in $\alpha$-position of the sulfur atom $\left(\mathrm{H}_{8}\right) .{ }^{1} \mathrm{H}$ NMR analysis of the P2EP1SP (Fig. 2) allows determining that its epoxy functionality is equal to 1.8 , corresponding to a phosphorus content of 6.1 w\%P. By modifying the thiol:epoxy ratio to $3: 3$, the P3SP was obtained. ${ }^{1} \mathrm{H}$ NMR analysis of the P3SP (Fig. 3) allows determining that there is no residual epoxy functions, corresponding to a phosphorus content of $10.0 \mathrm{w} \% \mathrm{P}$.

\subsection{Incorporation in epoxy matrix}

To evaluate their efficiency, the synthesized P-FR (P3SP and P2EP1SP) were formulated in a conventional epoxy matrix, i.e. DGEBA, cured with isophorone diamine (IPDA) (Fig. 4). DGEBA exhibits an aromatic structure leading to a rigid network with excellent mechanical properties and good chemical inertness. That is why DGEBA is widely used, especially in the production of

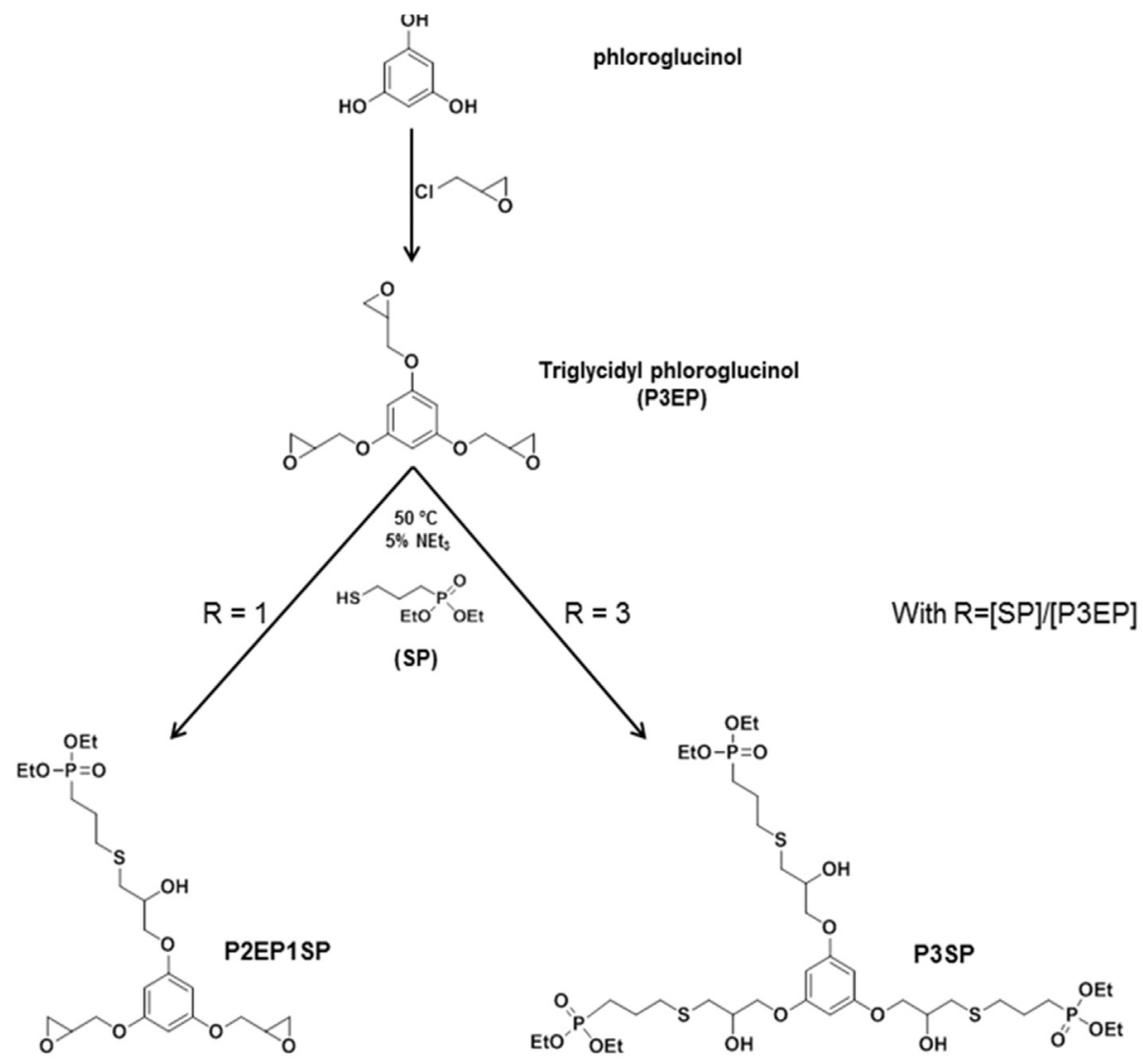

Scheme 1. Synthesis of the reactive P-FR: diglycidyl thiophosphonated phloroglucinol (P2EP1SP) and the additive P-FR tri-thiophosphonated phloroglucinol (P3SP). 


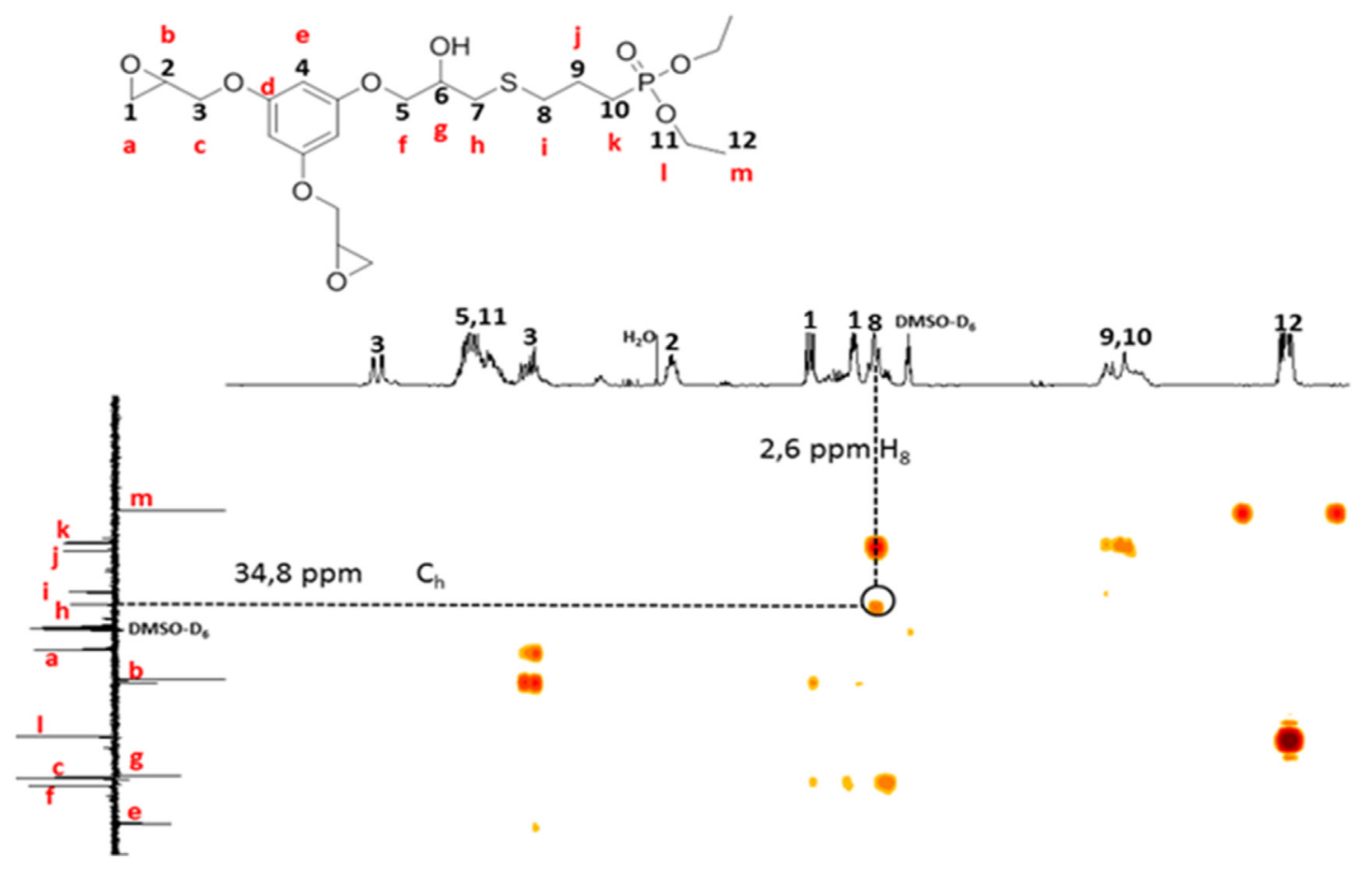

Fig. 1. HMBC $2 \mathrm{D}{ }^{1} \mathrm{H}-{ }^{13} \mathrm{C}$ NMR spectrum of the diglycidyl thiophosphonated phloroglucinol (P2EP1SP) in DMSO- $\mathrm{d}_{6}$.

coatings or high performance composites [27,28]. IPDA is a cycloaliphatic crosslinker and appears to provide a good balance between reactivity and network rigidity. The two P-FR were incorporated in a DGEBA-IPDA matrix according to the appropriate approach. The [epoxy]/[amine] ratio was kept equal to 2 in all the formulations. Different P-FR contents and thus different phosphorus (and sulfur) contents were used (Table 1) to assess the influence of this parameter. The sulfur content of the flame-retarded thermosets are systematically equal to the phosphorus ones. Curing was carried out using the following temperature program: $4 \mathrm{~h}$ at $80{ }^{\circ} \mathrm{C}$ followed by $10 \mathrm{~h}$ at $150{ }^{\circ} \mathrm{C}$. Seven thermosets were thus prepared, varying the phosphorus content from 1 to 3 w\% by both approaches.

A possible incompatibility between the matrix and the FR could lead to a partial phase segregation [5]. During early stages of curing, viscosity of the system decreases and may allow sedimentation or creaming of segregated phases. The homogeneity of the cured thermosets was studied by Scanning Electron Microscopy (SEM)

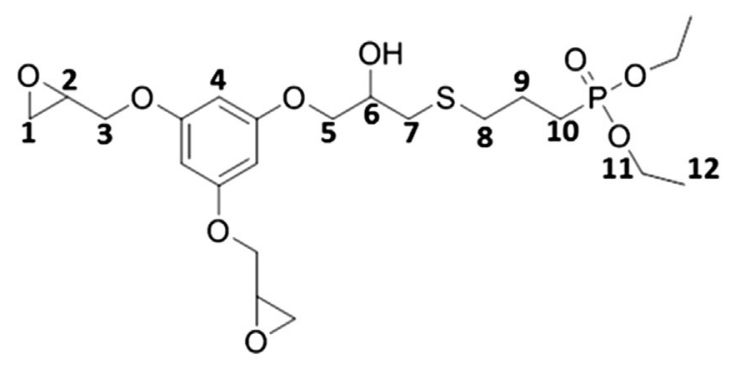

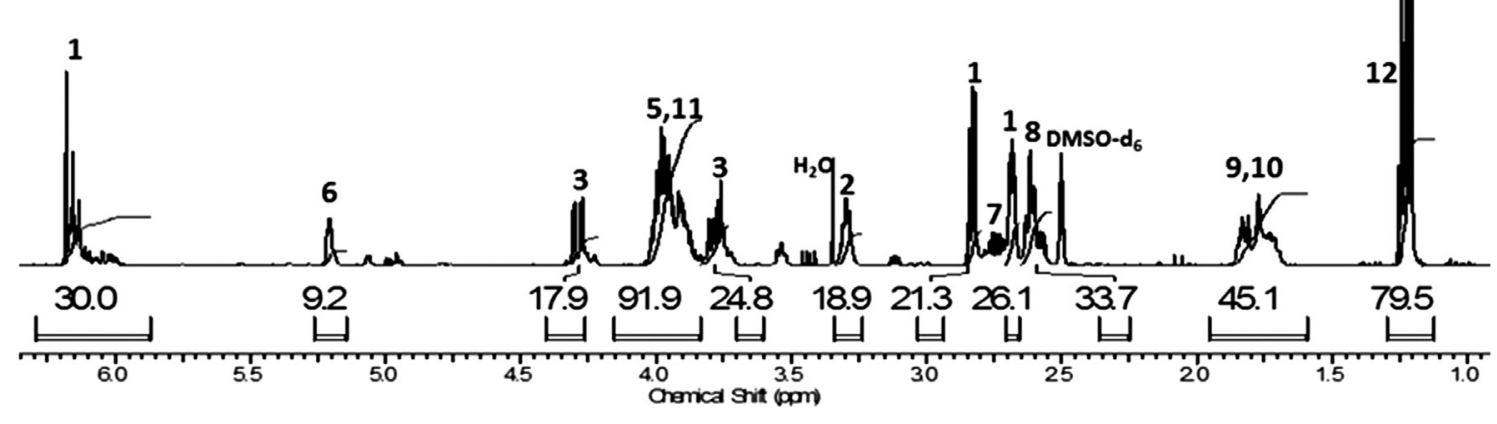

Fig. 2. ${ }^{1} \mathrm{H}$ NMR spectrum of the diglycidyl thiophosphonate phloroglucinol (P2EP1SP) in DMSO- $\mathrm{d}_{6}$. 


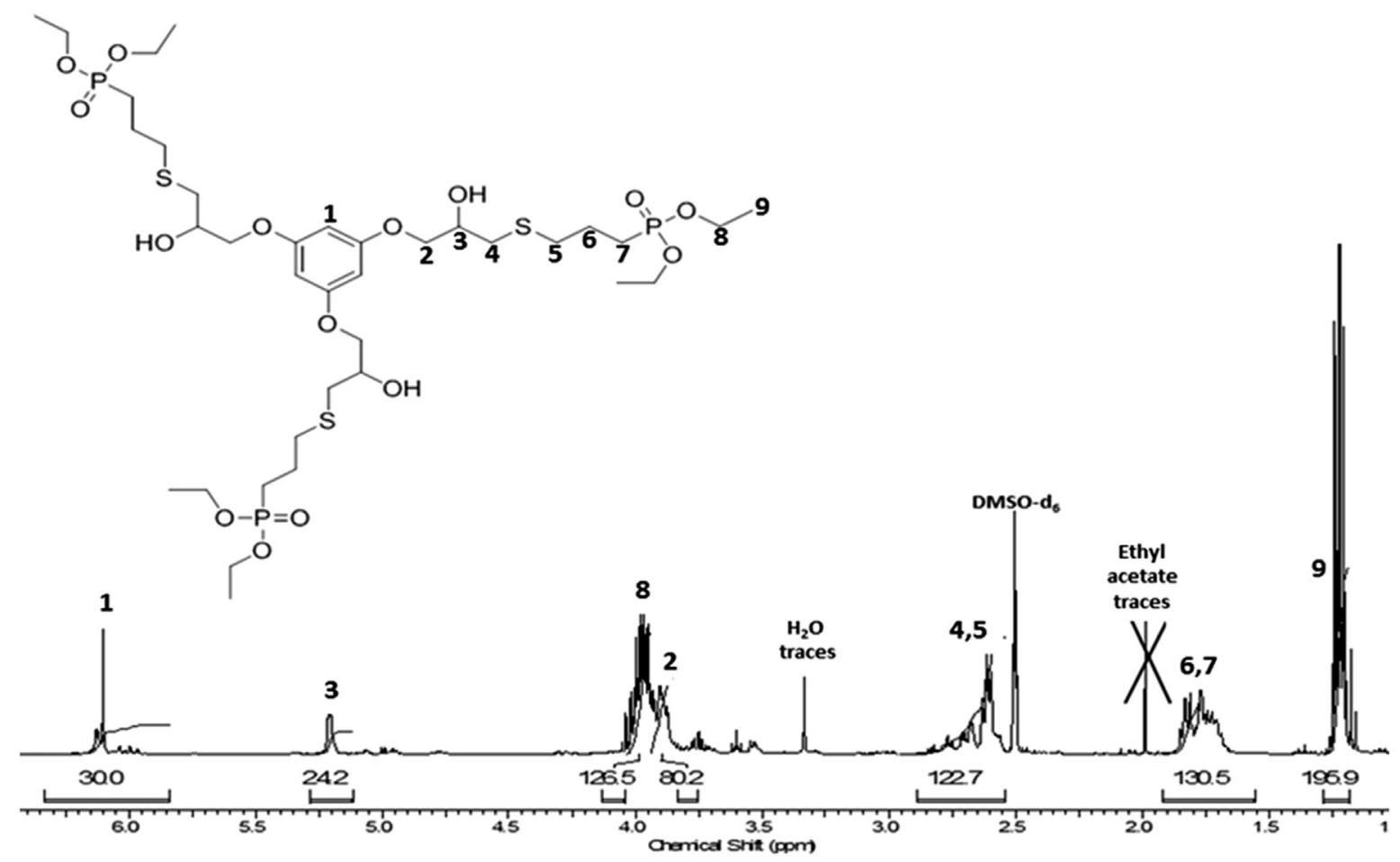

Fig. 3. ${ }^{1} \mathrm{H}$ NMR spectrum of the trithiophosphonate phloroglucinol (P3SP) in DMSO-d .

a)

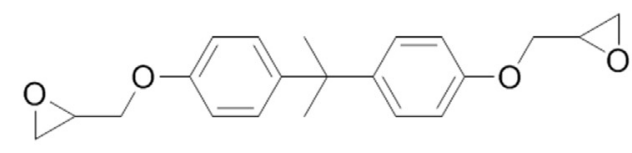

b)

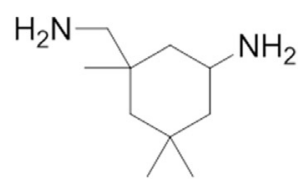

Fig. 4. a) Diglycidylether of Bisphenol A (DGEBA), b) Isophorone diamine (IPDA).

with Energy Dispersive X-ray technology (EDX). Results exhibited the good compatibility of both additive and reactive P-FR in all the formulations, avoiding phase segregation and leading to homogeneous thermosets.

\subsection{Characterization of the thermosets properties}

In this paper, the theoretical crosslink concentration is defined as the theoretical amount (in mole) of crosslink (or nitrogen atoms) in $200 \mathrm{~g}$ of the whole formulation (including additive and reactive compounds).
4.6. Differential Scanning Calorimetry (DSC) analyses of crosslinked thermosets

Physical properties of thermosets can be assessed by measuring their glass transition temperature ( $\mathrm{Tg}$ ) from DSC (Table 3). Usually, high $\mathrm{Tg}$ are targeted for the epoxy thermosets to reach both high thermal and mechanical properties. DSC analyses were performed on cross-linked thermosets.

The Tg values of the phosphorus-containing thermosets (Table 3 and Fig. 5) are lower than the Tg value of the P-FR-free DGEBA-IPDA matrix $\left(156^{\circ} \mathrm{C}\right)$. This effect increases with the P-FR content, i.e. with

Table 3

Data of the DSC, TG, PCFC and cone calorimeter analyses of all the prepared thermosets.

\begin{tabular}{|c|c|c|c|c|c|c|c|c|c|c|c|}
\hline \multirow[t]{2}{*}{ Thermosets } & \multirow{2}{*}{$\begin{array}{l}\text { Theoretical } \\
\text { crosslink } \\
\text { concentration } \\
\text { (moles of } \\
\text { crosslink/200 g) }\end{array}$} & \multirow{2}{*}{$\frac{\mathrm{DSC}}{\operatorname{Tg}\left({ }^{\circ} \mathrm{C}\right)}$} & \multicolumn{2}{|l|}{ TGA } & \multicolumn{3}{|l|}{ PCFC } & \multicolumn{4}{|c|}{ Cone calorimeter } \\
\hline & & & $\mathrm{T}_{10}\left({ }^{\circ} \mathrm{C}\right)$ & $w \%$ char at $700{ }^{\circ} \mathrm{C}$ & pHRR (W/g) & THR (kJ/g) & $\mathrm{EHC}(\mathrm{kJ} / \mathrm{g})$ & w\% residue & pHRR (W/g) & THR (kJ/g) & TTI (s) \\
\hline DGEBA-IPDA & 0.47 & 156 & 364 & 9 & 664 & 34.1 & 37.5 & 5.4 & 1306 & 23.0 & 86 \\
\hline 1\%P(P3SP) & 0.42 & 132 & 352 & 13 & 475 & 24.5 & 28.2 & $\mathrm{X}$ & $\mathrm{X}$ & $\mathrm{X}$ & $\mathrm{X}$ \\
\hline 2\%P(P3SP) & 0.38 & 113 & 337 & 16.1 & 360 & 23.9 & 28.5 & $\mathrm{X}$ & $\mathrm{X}$ & $\mathrm{X}$ & $\mathrm{X}$ \\
\hline 3\%P(P3SP) & 0.33 & 88 & 325 & 19.3 & 240 & 20.8 & 25.8 & 39.7 & 523 & 11.6 & 69 \\
\hline 1\%P(P2EP1SP) & 0.44 & 139 & 346 & 15.1 & 438 & 25.1 & 29.9 & $\mathrm{X}$ & $\mathrm{X}$ & $\mathrm{X}$ & $\mathrm{X}$ \\
\hline 2\%P(P2EP1SP) & 0.41 & 120 & 333 & 20 & 291 & 22.1 & 27.6 & $\mathrm{X}$ & $\mathrm{X}$ & $\mathrm{X}$ & $\mathrm{X}$ \\
\hline 3\%P(P2EP1SP) & 0.38 & 93 & 323 & 25.5 & 211 & 18.8 & 25.2 & 47.8 & 584 & 10.1 & 56 \\
\hline
\end{tabular}




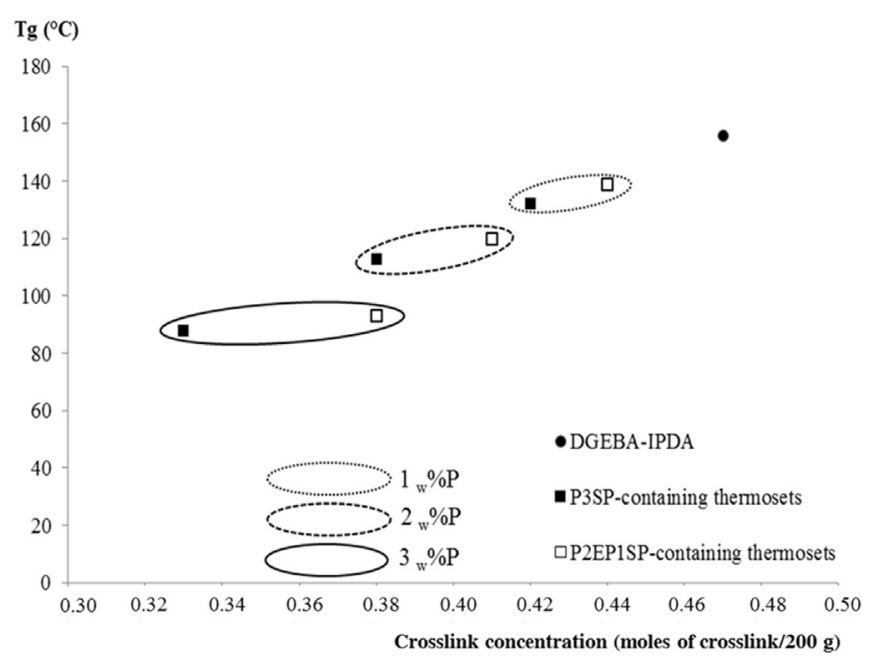

Fig. 5. Tg values of all the thermosets versus their theoretical crosslink concentrations.

the phosphorus content. Comparing the additive approach to the reactive one, it is observed that for equal phosphorus contents, the $\mathrm{Tg}$ values of the P2EP1SP-containing thermoset is about $6{ }^{\circ} \mathrm{C}$ higher. Indeed, for a phosphorus content of $3 \mathrm{w} \%$, $\mathrm{Tg}$ is reduced until $88^{\circ} \mathrm{C}$ by the P-FR P3SP, compared to $93{ }^{\circ} \mathrm{C}$ by the P-FR P2EP1SP. This slight difference is not significant and it is considered that for equal phosphorus contents, both approaches impacts similarly the $\mathrm{Tg}$ value of the flame-retarded thermosets. This decrease of Tg values is assumed to be due to the lower crosslink concentrations of the PFR-containing thermosets (Table 3) compared to the DGEBA-IPDA one. Crosslink concentrations are calculated by counting the amount of nitrogen atoms in $200 \mathrm{~g}$ of formulation. It is also observed that (2\% (P3SP) and 3\% P(P2EP1SP) thermosets presents equal crosslink concentrations (0.38) but have different $\mathrm{Tg}$ values, $113^{\circ} \mathrm{C}$ and $93{ }^{\circ} \mathrm{C}$ respectively. It has to be considered that the P3SPcontaining material contains $55.8 \mathrm{w} \%$ of DGEBA, whereas the P2EP1SP-containing one contains only $34.4 \mathrm{w} \%$. In the present example, for equal crosslink concentration, the additive approach reduces less the $\mathrm{Tg}$ values of the thermosets. In the case of the additive approach, the decrease of the crosslink concentration is attributed to a plasticizing effect due to the incorporation of the additive compound P3SP in the thermoset network. P3SP creates space between network chains, thus reducing the crosslink concentration and the $\mathrm{Tg}$ of the thermoset. For the reactive approach, the decrease of the crosslink concentration by increasing the phosphorus content can be related to the lower epoxy functionality of the reactive P-FR P2EP1SP equal to 1.8, compared to the epoxy functionality of the DGEBA which is equal to 2. This low P2EP1SP epoxy functionality induces a decrease of the average epoxy functionality of the system, leading to a partial termination of the growing network and finally to a lower crosslink concentration and a lower Tg value of the P2EP1SP-containing thermosets.

\subsection{Thermal properties and flammability of the epoxy thermosets}

Phosphorus-containing FR are known for their various flameretardancy mechanisms. They can act in gas and/or in condensed phases [29]. In the gas phase, they can act by flame inhibition. Thermal decomposition of phosphorus group can generate radical species $\mathrm{PO}_{2} \cdot \mathrm{PO} \cdot$ and $\mathrm{HPO} \cdot$, which scavenge the $\mathrm{H}^{\cdot}$ and $\mathrm{OH} \cdot$ radicals, slowing down the combustion and even reducing the combustion efficiency. In the condensed phase, chains dehydroxylation occurs due to the action of phosphoric acid onto the hydroxyl groups, leading to conjugated molecules, and then to polyaromatic structures by Diels-Alder cyclization [3]. The formed char can act as a barrier against heat and gas $\left(\mathrm{O}_{2}\right.$ and pyrolysis gases).

The flammability of the different thermosets was assessed according to parameters such as high temperature char amounts, heat release rate or total heat released during decomposition. Thermosets were thus characterized by thermogravimetric analysis (TGA), pyrolysis combustion flow calorimetry (PCFC) analyses and by cone calorimeter to highlight the effects of the P-FR on the flammability of the thermosets at different scales.

\subsection{Thermogravimetric analyses (TGA) of flame retarded thermosets}

TG analyses were performed to assess the influence of two P-FR on thermal stability and charring of the flame-retarded thermosets. $\mathrm{T}_{10}$ represents the temperature at which the material loses $10 \%$ of its initial mass. Char content at $700{ }^{\circ} \mathrm{C}$ and $\mathrm{T}_{10}$ values are given in Table 3.

Concerning the P3SP-containing thermosets (Fig. 6A), a loss of thermal stability can be observed compared to the DGEBA-IPDA matrix. Moreover this loss of thermal stability seems to be a function of the phosphorus content, i.e. of the P-FR content. Indeed, $\mathrm{T}_{10}$ was reduced from $364^{\circ} \mathrm{C}$ for the DGEBA-IPDA matrix, to $352{ }^{\circ} \mathrm{C}$ for the $1 \% \mathrm{P}(\mathrm{P} 3 \mathrm{SP})$, to $337^{\circ} \mathrm{C}$ for the $2 \% \mathrm{P}$ (P3SP) and to $325^{\circ} \mathrm{C}$ for the 3\%P (P3SP). Fig. 6B exhibits the same phenomenon on the P2EP1SPcontaining thermosets, the thermal stability was reduced down to $323{ }^{\circ} \mathrm{C}$ for the $3 \% \mathrm{P}(\mathrm{P} 2 \mathrm{EP} 1 \mathrm{SP})$. For similar phosphorus contents, the losses of thermal stability are similar for the two approaches. These lower degradation temperatures are assigned to the early stage of decomposition of phosphorus-containing groups. Price et al. [30] described the phosphonic-ester decomposition ranging from 300 to $340{ }^{\circ} \mathrm{C}$ by alkyl chain loss. It may be assumed that phosphonicester decomposition generates radical species which initiate the matrix decomposition and the char formation. The different phosphorus contents of the P2EP1SP and P3SP, $6.1 \mathrm{w} \%$ and $10.0 \mathrm{w} \%$ respectively, induces higher P-FR content in the case of the reactive approach for a given phosphorus content. Thus, the thermal stability of the flame-retarded thermosets only depends on the phosphorus content and is not influenced by the covalent bonding brought by the reactive approach.

In addition, Fig. $6 \mathrm{~A}$ and $6 \mathrm{~B}$ also exhibit that phosphoruscontaining thermosets provide a higher amount of stable residue at high temperature than the thermoset DGEBA-IPDA without any P-FR. This charring effect increased in function of the phosphorus content and is more important with the reactive approach than with the additive one. Indeed, for equal phosphorus content the char contents at $700{ }^{\circ} \mathrm{C}$ are increased from $9.0 \mathrm{w} \%$ for the DGEBAIPDA thermoset, to $19.3 \mathrm{w} \%$ for the $3 \% \mathrm{P}(\mathrm{P} 3 \mathrm{SP})$ and to $25.5 \mathrm{w} \%$ for the 3\%P (P2EP1SP) (Fig. 6C). This difference could show that the action of the P-FR in the condensed phase is favored by the covalent bonding between the P-FR and the matrix. This assumption is consistent with the result of the SEM-EDX characterization. Indeed, the char from 3\%P(P3SP) thermoset contains 7.0 w\% of phosphorus, i.e. $45 \%$ of the initial phosphorus content while the char from $3 \%$ $\mathrm{P}(\mathrm{P} 2 \mathrm{EP} 1 \mathrm{SP})$ contains 9.6 w\% of phosphorus, i.e. $82 \%$ of the initial phosphorus content (Fig. 6D).

However, it is assumed that for equal phosphorus content, the significant difference of composition due to the different P-FR contents may also influence the charring ability of the phosphoruscontaining thermosets.

\subsection{Pyrolysis combustion flow calorimetry (PCFC)}

To assess the flame retardant properties of the two P-FR 

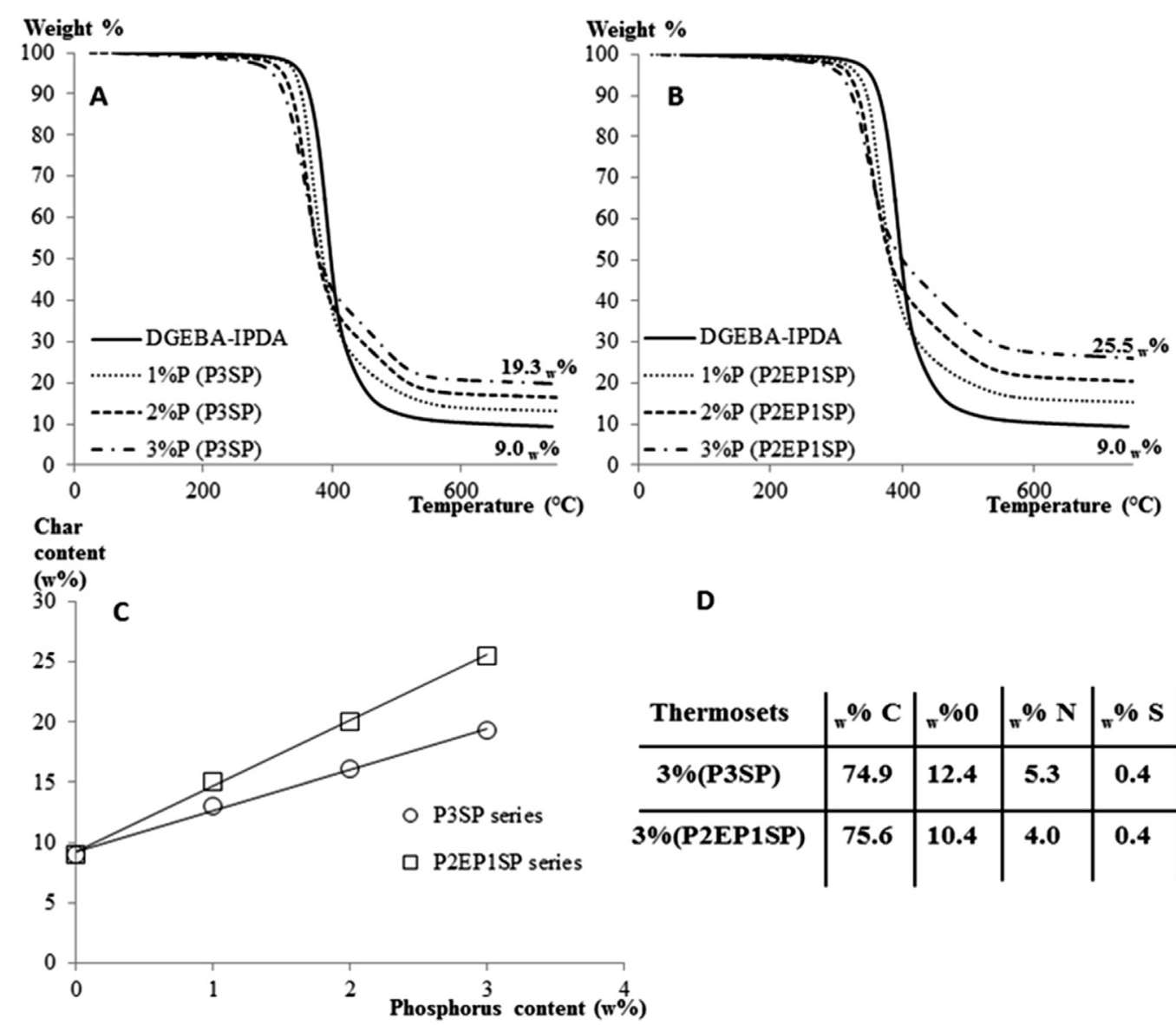

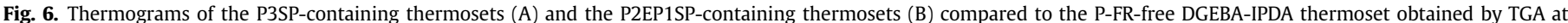

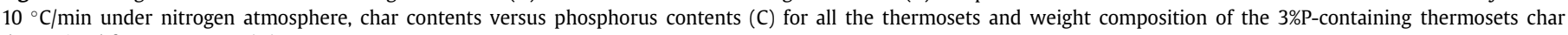
determined from MEB-EDX (D).

synthesized, thermosets were characterized by pyrolysis/combustion flow calorimetry. PCFC analyses correspond to anaerobic thermoset pyrolysis followed by the high temperature oxidation of decomposition products (complete combustion) [18].

pHRR is the maximal value of the heat release. The total heat released (THR) was obtained by integration of PCFC curves. The effective heat of combustion (EHC) represents the released heat by mass loss. It is calculated as the ratio between the THR and the mass loss measured in TGA. TGA values are believed to be more accurate. It was checked previously by weighing PCFC crucibles before and after test that PCFC residues are most generally consistent with TGA residues at $700{ }^{\circ} \mathrm{C}$. The main difference that is usually observed between PCFC and TGA is a shift in temperature of decomposition peak due to the difference of heating rate. These parameters values are given in Table 3.

Firstly, the loss of thermal stability observed by TGA for the phosphorus-containing thermosets is confirmed by fuels release at lower temperature than for the DGEBA-IPDA thermoset. For instance, fuels release starts around $330{ }^{\circ} \mathrm{C}$ for the DGEBA-IPDA thermoset, compared to $280{ }^{\circ} \mathrm{C}$ for the $3 \% \mathrm{P}(\mathrm{P} 3 \mathrm{SP})$ thermoset and $270{ }^{\circ} \mathrm{C}$ for the $3 \% \mathrm{P}$ (P2EP1SP) (Fig. 7). Fig. 7A and 7B shows that the thermal stability decreases while the phosphorus content increases by the two approaches.

Like TGA, for equal phosphorus content, the additive P-FR P3SP and the reactive P-FR P2EP1SP impact equally the thermal stability of the thermoset. Indeed, Fig. $7 \mathrm{C}$ shows that the thermal stability of the $3 \% \mathrm{P}$-containing thermosets are around $275{ }^{\circ} \mathrm{C}$ and the $1 \% \mathrm{P}-$ containing thermosets are similar and around $300{ }^{\circ} \mathrm{C}$. The discrepancy observed between TGA and PCFC analyses may be due to the higher heating ramp of PCFC analyses $\left(1^{\circ} \mathrm{C} / \mathrm{S}\right)$ than of TGA $\left(10^{\circ} \mathrm{C} / \mathrm{min}\right)$.

Concerning the peak of heat released rate (pHRR), the phosphorus-containing thermosets exhibit lower values than the DGEBA-IPDA thermoset (Table 3, Fig. 7A and 7B), enhancing the good flame retardant properties of the P-FR synthesized. For similar phosphorus contents, the pHRR of the P3SP and the P2EP1SPcontaining thermosets are similar (Fig. 7C, 7E); pHRR is reduced from $664 \mathrm{~W} / \mathrm{g}$ for the DGEBA-IPDA thermoset to $240 \mathrm{~W} / \mathrm{g}$ for the $3 \%$ (P3SP) thermoset and to $211 \mathrm{~W} / \mathrm{g}$ for the $3 \%$ (P2EP1SP) thermoset, i.e. a decrease of $64 \%$ and $68 \%$ respectively. The decrease of the pHRR follows the same trend for both approaches (Fig. 7E). The THR of the phosphorus-containing thermosets are also reduced compared to the DGEBA-IPDA thermoset. For equal phosphorus content, the THR values of the P3SP-containing thermosets are slightly lower than the P2EP1SP-containing ones. THR is reduced from $34.1 \mathrm{~kJ} / \mathrm{g}$ for the DGEBA-IPDA thermoset to $20.8 \mathrm{~kJ} / \mathrm{g}$ for the $3 \%$ $\mathrm{P}$ (P3SP) thermoset and to $18.8 \mathrm{~kJ} / \mathrm{g}$ for the $3 \%$ (P2EP1SP) thermoset, i.e. a decrease of $39 \%$ and $45 \%$ respectively. From the char yield obtained by TGA and the THR, it is possible to calculate the EHC values (Table 3). The EHC values are reduced by the two approaches, showing the lower calorific power of the gas releases during the thermal degradation. Since the char content and the THR are higher with the reactive approach than with the additive one; it allows equivalent EHC for both approaches. The decrease of these 

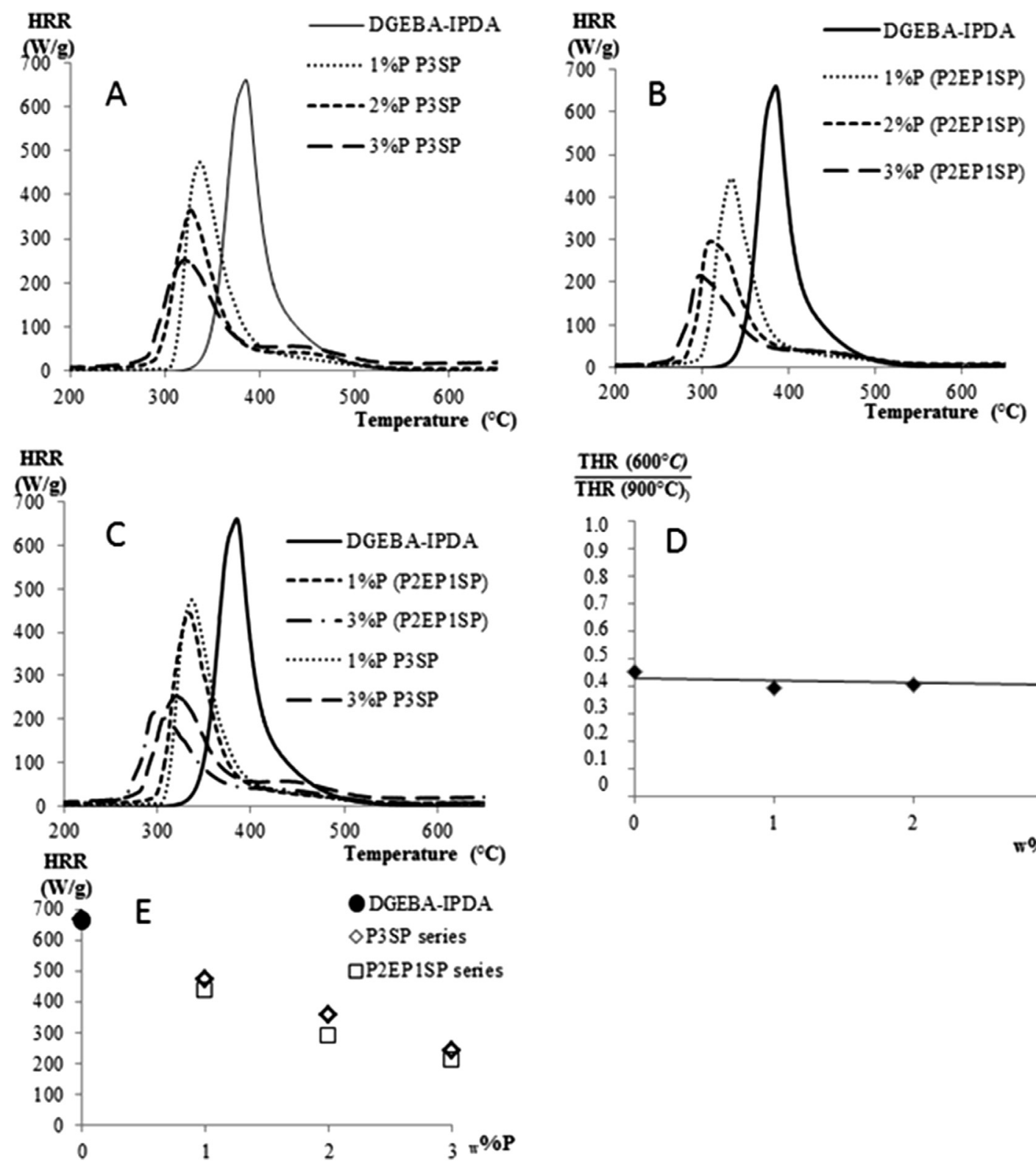

$\frac{\operatorname{THR}\left(600^{\circ} \mathrm{C}\right)}{\operatorname{THR}\left(900^{\circ} \mathrm{C}\right)}$

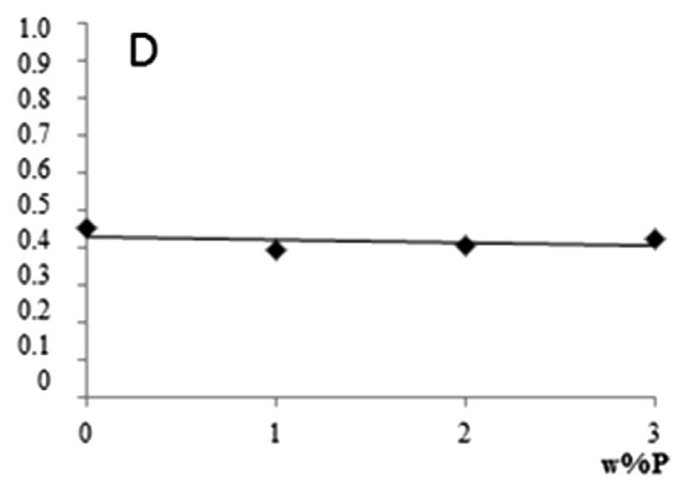

Fig. 7. PCFC curves of the P3SP-containing thermosets (A), P2EP1SP-containing (B) thermosets compared to the P-FR-free DGEBA-IPDA and comparison of P3SP vs P2EP1SPcontaining (C) thermosets, $\left(\mathrm{THR}_{600} / \mathrm{THR}_{900}\right)$ obtained by PCFC at $1{ }^{\circ} \mathrm{C} / \mathrm{s}$ on P3SP-containing thermoset (D) and pHRR vs phosphorus content (E).

three parameters (pHRR, THR and EHC) appears to be a function of the phosphorus content and is not influenced by the covalent bonding of the phosphorus moieties to the matrix. These effects exhibit the good flame retardant properties of the P-FR synthesized.

TGA-FTIR analyses show the release of phosphorus-and-sulfur containing gases during the thermal degradation of the flame retarded thermosets. The FTIR spectrum of the evolved gases during thermal degradation of $3 \% \mathrm{P}(\mathrm{P} 3 \mathrm{SP})$ at $350^{\circ} \mathrm{C}(\mathrm{S} . \mathrm{I} .2)$ shows bands of $\mathrm{P}-\mathrm{O}-\mathrm{CH} 3$ (bending, $850 \mathrm{~cm}^{-1}$ ), $\mathrm{P}=\mathrm{O}$ (stretching, $1180 \mathrm{~cm}^{-1}$ and $1250 \mathrm{~cm}^{-1}$ ) [31] and S-O-R (stretching, $750 \mathrm{~cm}^{-1}$ ) bonds. These characteristic bands are present in the gases evolved from the TGA of all the P-FR-containing thermosets. However, taking the $\mathrm{CO}_{2}$ band at $1345 \mathrm{~cm}^{-1}$ as reference in the spectra at the maximum of gas release rate, the intensities of these bands are more intense for the thermosets flame-retarded by the additive approach than by the reactive one, we assume that it could be due to an easier releasing of phosphorus-containing gas by the additive approach.
A PCFC experiment which consists in plotting the ratio between the THR obtained in incomplete combustion conditions at $600{ }^{\circ} \mathrm{C}$ and the THR obtained in complete combustion at $900{ }^{\circ} \mathrm{C}\left(\mathrm{THR}_{600} /\right.$ $\mathrm{THR}_{900}$ ) versus the phosphorus content allows to highlight the radical scavenging action of a P-FR [32]. Fig. 7D exhibits that the $\mathrm{THR}_{600} / \mathrm{THR}_{900}$ ratio is constant versus the phosphorus content for the P3SP-containing thermoset. The same result is observed on the P2EP1SP-containing thermosets. These results demonstrate that the phosphorus-and-sulfur containing gases released during the thermal degradation have no radical scavenging action in the gas phase.

\subsection{Cone calorimeter analyses}

PCFC does not allow assessing some phenomenon as barrier effect due to char formation. To assess the real potential of the synthesized P-FR, the 3\%P(P3SP) and the 3\% (P2EP1SP) thermosets 

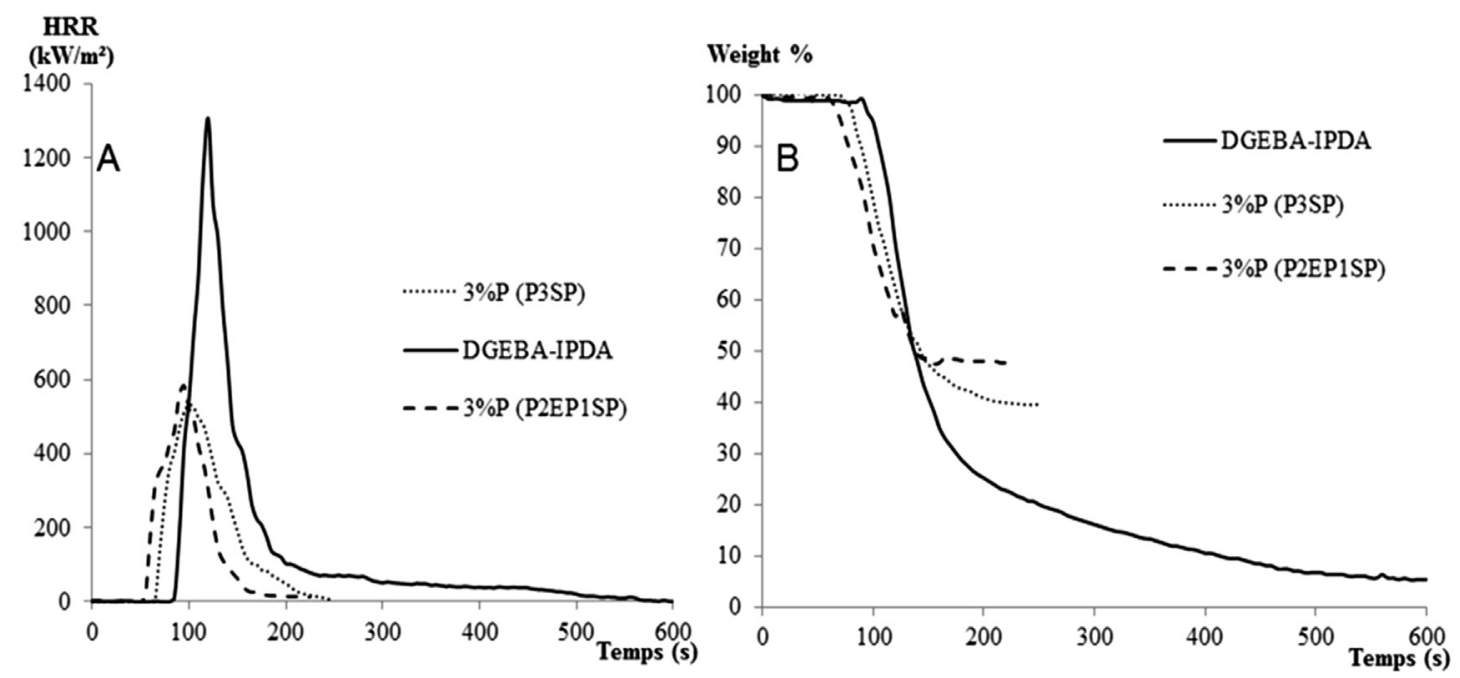

Fig. 8. Heat release rate curves (A) and mass monitoring curves (B) of the $3 \mathrm{w} \% \mathrm{P}$-containing thermosets obtained with cone calorimeter at an irradiance of $35 \mathrm{~kW} / \mathrm{m}^{2}$.

were characterized using the cone calorimeter and compared to the DGEBA-IPDA. The cone calorimeter reproduces the conditions observed in a real fire. pHRR, THR, Times To Ignition (TTI) and w\%residue values are given in Table 3.

The two P-FR provide an intumescent behavior to the flameretarded thermosets. Fig. $8 \mathrm{~A}$ presents the HRR curves of the $3 \% \mathrm{P}-$ containing thermosets compared to the DGEBA-IPDA thermoset. The loss of thermal stability observed by TGA and PCFC leads to a lower time to ignition (TTI) for the P-FR-containing thermosets. Indeed the TTI of the DGEBA-IPDA, 3\%P(P3SP) and 3\%P(P2EP1SP) thermosets are 86, 69 and $56 \mathrm{~s}$ respectively. The pHRR are equally reduced by the two approaches, a decrease of around 60\% compared to the DGEBA-IPDA thermoset is observed. THR values are reduced from $23.0 \mathrm{~kJ} / \mathrm{g}$ to $11.6 \mathrm{~kJ} / \mathrm{g}$ for the $3 \% \mathrm{P}(\mathrm{P} 3 \mathrm{SP})$ thermoset and to $10.1 \mathrm{~kJ} / \mathrm{g}$ for the $3 \% \mathrm{P}(\mathrm{P} 2 \mathrm{EP} 1 \mathrm{SP})$ thermoset. These THR values correspond to a decrease of $50 \%(3 \% \mathrm{P}(\mathrm{P} 3 \mathrm{SP}))$ and $56 \%(3 \%$ $\mathrm{P}(\mathrm{P} 2 \mathrm{EP} 1 \mathrm{SP})$ ) of the DGEBA-IPDA THR value, compared to $39 \%$ and $45 \%$ by PCFC respectively. The higher decrease of the THR during cone calorimeter tests is due to the physical action of the formed char, which protects the underlying thermoset and reduces the amount of thermoset which contributes to the combustion. It is likely to note that P-FR-containing thermosets also show lower TTE (Time To Extinction) than that of P-FR-free DGEBA-IPDA thermoset (Fig. 8).
Concerning the residue contents ( $\mathrm{w} \%$ residue), significant differences between TGA and cone calorimeter values are observed. Fig. $8 \mathrm{~B}$ presents the mass monitoring curves obtained on the DGEBA-IPDA and the 3\%P-containing thermosets and show w\% residue values of 5.4, 39.7 and $47.8 \mathrm{w} \%$ for the DGEBA-IDPA, 3\%P(P3SP) and $3 \% \mathrm{P}(\mathrm{P} 2 \mathrm{EP} 1 \mathrm{SP})$, respectively. The same trend is observed by TGA: for similar phosphorus content, the reactive P-FR (P2EP1SP) favors more the charring than the additive one (P3SP). However, significant discrepancies are observed between the w\%char (TGA) and the ${ }_{\mathrm{w}} \%$ residue (cone calorimeter): $3 \% \mathrm{P}(\mathrm{P} 3 \mathrm{SP})$ produces 19.3 w\% char by TGA, compared to 39.7 w\%residue by cone calorimeter test and $3 \% \mathrm{P}(\mathrm{P} 2 \mathrm{EP} 1 \mathrm{SP})$ produces $25.5 \mathrm{w} \%$ char by TGA, compared to 47.8 w\%residue by cone calorimeter test. This difference is due to the intumescence of the system. Indeed, from the cone calorimeter, the two P-FR lead to intumescent residues, which act as barrier to the external heat flux and to the gas flow. This intumescent effect is attributed to the chain degradation, which generate gases. But it is mainly due to the adequate viscosity of the system during charring, allowing the simultaneous swelling/charring of the thermoset during degradation. On the contrary for P-FR-free thermoset, the residue is lower in cone calorimeter probably due to the thermooxidation at the end of the test. The reactive P-FR P2EP1P seems to favor this intumescent effect more than the additive one P3SP. Indeed, the $3 \% \mathrm{P}(\mathrm{P} 3 \mathrm{SP})$ produces a $10 \mathrm{~cm}$ height residue (Fig. 9B)

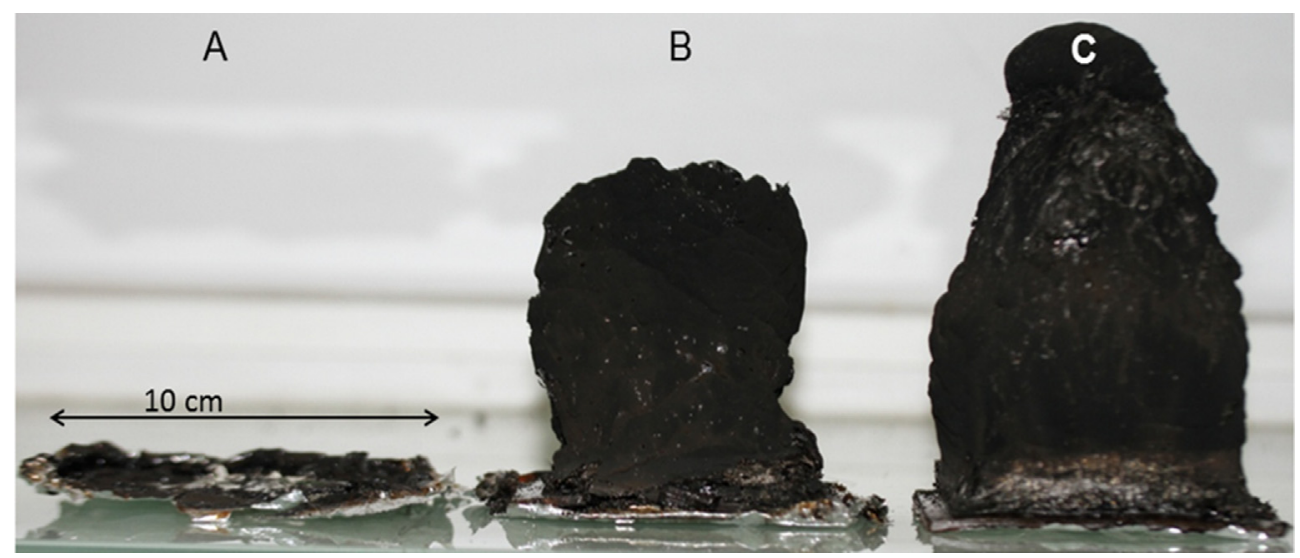

Fig. 9. Pictures of the cone residues: DGEBA-IPDA (A), 3\% P3SP (B) and 3 \% P P2EP1SP (C) thermosets obtained by cone calorimeter. 

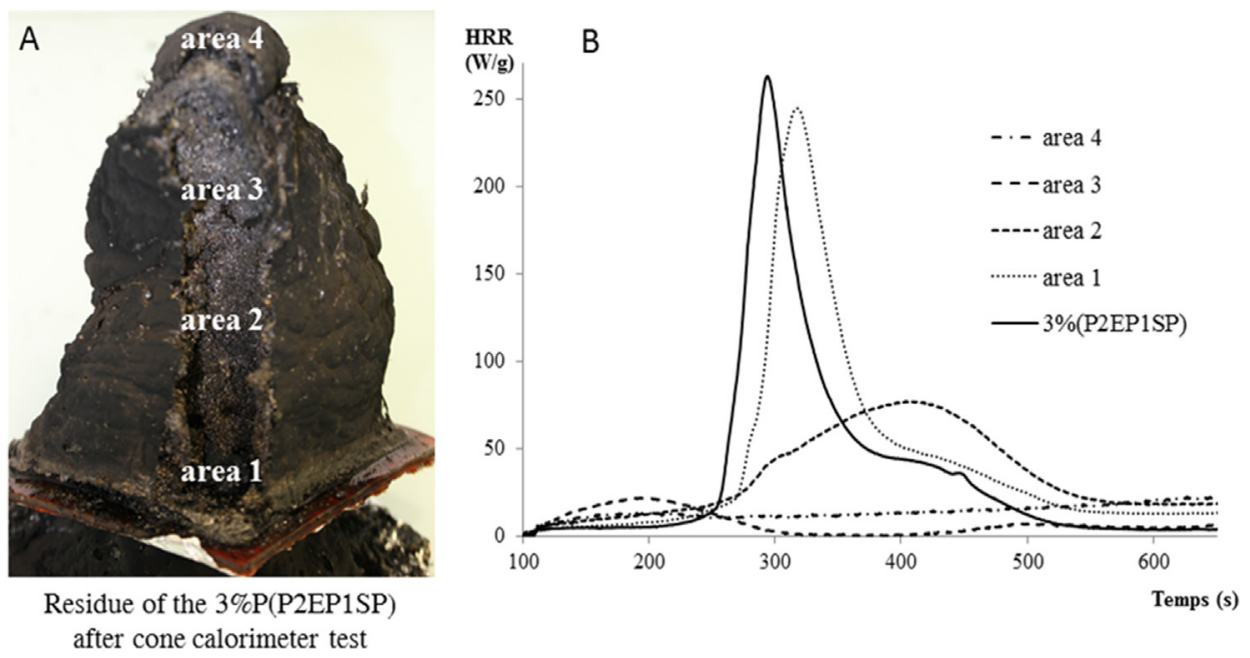

Fig. 10. PCFC curves of the cone calorimeter residue at different heights of the $3 \% \mathrm{P}(\mathrm{P} 2 \mathrm{EP} 1 \mathrm{SP})$ thermoset obtained at $1{ }^{\circ} \mathrm{C} / \mathrm{s}$.

whereas the $3 \% \mathrm{P}(\mathrm{P} 2 \mathrm{EP} 1 \mathrm{SP})$ produces a $15 \mathrm{~cm}$ height residue (Fig. 9C) (compared to $0 \mathrm{~cm}$ height residue for the DGEBA-IPDA thermoset, Fig. 9A). It may be due to the more efficient condensed phase action of the P-FR favored by the reactive approach.

Concerning the THR values, it is noted that the values from the cone calorimeter tests are lower than from PCFC analyses. Indeed, the PCFC THR of the DGEBA-IPDA is equal to $34.1 \mathrm{~kJ} / \mathrm{g}$, compared to $23.0 \mathrm{~kJ} / \mathrm{g}$ from cone calorimeter test. This result may be due to the incomplete combustion during the cone calorimeter test while at PCFC the combustion is complete. The cone calorimeter THR values of the 3\%P-containing thermosets are also lower than their PCFC equivalent. In his case, it is due to the incomplete combustion during cone calorimeter test and mostly to the non-degraded part of the thermoset. The fraction of the final residue composed of non-degraded initial thermoset is not considered in the following discussion. The composition of the char obtained from cone calorimeter tests was assessed by SEM-EDX. To obtain a significant result, the samples SEM-EDX are picked up from the top to the bottom of the residue but the non-degraded initial thermoset below the char was not taken into account. Table 2 reports the elemental composition of the residues. As from SEM-EDX analyses of the chars obtained by TGA, the residue of the $3 \% \mathrm{P}(\mathrm{P} 3 \mathrm{SP})$ present a lower phosphorus content than the residue of the 3\%P(P2EP1SP) thermoset, showing that the reactive approach favors more the action in the condensed phase than the additive one. The lower carbon content of the cone calorimeter residue compared to the PCFC char is due to the partial oxidation of the residue after the flame out.

To highlight the insulating character of the intumescent char obtained, different samples were picked-up at different heights of the residue and characterized by PCFC. Fig. 10 highlights the insulating character of the intumescent residue produced by the $3 \%$ $\mathrm{P}$ (P2EP1SP) thermoset. PCFC analyses exhibit that the top of the residue (area 4 ) is totally degraded while the samples of the middle of the residue (areas 2 and 3) can still release heat and the sample of the bottom of the residue (area 1) presents a PCFC curve similar to the initial thermoset. The intumescent effect of the char prevents the decomposition of the underlying material by insulating it from heat. It is likely to note that these biobased P-FR systems allow intumescence while usually this effect is provided by a combination of an acid source for the charring and a blowing agent for the swelling of the char [33].

\section{Conclusion}

In this study, two new biobased phosphorus-and-sulfurcontaining flame retardants have been successfully synthesized from a biobased phenolic compound: phloroglucinol. It leads to an additive P-FR and a reactive one which differ by the presence of reactive epoxy functions. The flame retardant properties of these two P-FR were assessed in a conventional DGEBA-IPDA matrix. These two P-FR negatively impact the thermoset network properties by reducing its crosslink concentration and thus its glass transition temperature. Even if for equal phosphorus content, the reactive approach allows keeping higher crosslink concentration, the impact on the glass transition temperature is similar. For the additive approach this effect was attributed to a plasticizing effect while for the reactive approach it is attributed to a decrease of the crosslink rate due to the average epoxy functionality of the epoxy monomers lower than 2. TGA results highlight the more efficient action of P2EP1SP in condensed phase (charring) provided by the covalent bonding between the P-FR and the matrix. The PCFC analyses exhibit similar reduction of the pHRR, the THR and the EHC by the two approaches. The release of phosphorus-and-sulfurcontaining gases was showed by TGA-FTIR but these gases seem to have no radical scavenging action in the gas phase. Finally, the cone calorimeter tests exhibit the physical action of the char effect, leading to a huge intumescent effect and to an insulating residue, which protects the underlying thermoset from the heat and oxygen flow during thermal decomposition. The higher charring effect brought by the reactive approach favors the intumescence of the system, leading to more expanded char foam.

This work proves the potential of the biobased phenolic compound to be used as aromatic raw material for the synthesis of additive or reactive flame retardant. Overall, the reactive approach seems to be more promising than the additive one concerning the epoxy thermoset fire-retardancy.

\section{Appendix A. Supplementary data}

Supplementary data related to this article can be found at http:// dx.doi.org/10.1016/j.polymdegradstab.2015.07.015.

\section{References}

[1] REACH, Commission of regulation (EC) No 552/2009, Official J. Eur. Union, L 
$164 / 17$.

[2] RoHS, Directive 2002/95/EC of the european parliament and of the council, Official Journal of the European Union, L 37/19.

[3] S. Lu, I. Hameton, Recent developments in the chemistry of halogen-free flame retardant polymers, Prog. Polym. Sci. 27 (8) (2002) 1661-1712.

[4] E.N.G.E.J. Walsh, R.W. Parry, L.D. Quin, Washington DC, in: ACS Symposium Series 46. Phosphorus Chemistry. Development in American Science, 1992, p. 218. XIII, XXIX.

[5] R. Ménard, C. Negrell, L. Ferry, R. Sonnier, G. David, Synthesis of biobased flame retardant. Characterization of flame retardancy in epoxy thermosets, Pure Appl. Chem. 86 (11) (2014) 1637-1650.

[6] R. Ménard, C. Negrell, L. Ferry, R. Sonnier, G. David, Synthesis of new flameretardants by radical chain transfer copolymerization of glycidyl methacrylate an dimethoxy-phosphorylmethyl methacrylate, Eur. Polym. J. 57 (2014) 109-120.

[7] R. Auvergne, S. Caillol, G. David, B. Boutevin, J.-P. Pascault, Biobased thermosetting epoxy: present and future, Chem. Rev. 114 (2) (2014) 1082-1115.

[8] H. Ren, J. Sun, B. Wu, Q. Zhou, Synthesis and properties of a phosphoruscontaining flame-retardant epoxy resin based on bis-phenoxy (3-hydroxy) phenyl phosphine oxide, Polym. Degrad. Stab. 92 (6) (2007) 956-961.

[9] U. Braun, A.I. Balabanovich, B. Schartel, U. Knoll, J. Artner, M. Ciesielski, M. Döring, R. Perez, J.K.W. Sandler, V. Alstädt, D. Hoffman T Pospiech, Influence of the oxidation state of phosphorus on the decomposition and fire behaviour of flame-retarded epoxy resin composites, Polymer 47 (26) (2006) 8495-8508.

[10] C. Xie, B. Zeng, H. Gao, Y. Xu, W. Luo, X. Liu, L. Dai, Improviong thermal and flame-retardant properties of epoxy resins by a novel reactive phosphoruscontaining curing agent, Polym. Eng. Sci. 54 (5) (2014) 1192-1200.

[11] D. Kyriacos, Fire Retardants for Polymers, GEM-Chem, 2012, ISBN 9789078546269.

[12] Z. Zheng, B.W.T.Y.S. Liu, X. Cui, H. Wang, Preparation of a novel phosphorusand nitrogen- containing flame retardant and its synergistic effect in the intumescent flame-retarding polypropylene system, Polym. Compos. (2014), http://dx.doi.org/10.1002/pc.23069.

[13] L. Gu, G. Chen, Y. Yao, Two novel phosphorus-nitrogen-containing halogenfree flame retardants of high performance for epoxy resin, Polym. Degrad. Stab. 108 (0) (2014) 68-75.

[14] S. Ma, X. Liu, Y. Jiang, L. Fan, J. Feng, J. Zhu, Synthesis and properties of phosphorus-containing bio-based epoxy resin from itaconic acid, Sci. China Chem. 57 (3) (2014) 379-388.

[15] G. Lligadas, J.C. Ronda, M. Galià, V. Cadiz, Development of novel phosphoruscontaining epoxy resins from renewable resources, J. Polym. Sci. Part A Polym. Chem. 44 (23) (2006) 6717-6727.

[16] B. Szolnoki, A. Toldy, P. Konrad, G. Szebenyi, G. Marosi, Comparison of additive and reactive phosphorus-based flame retardants in epoxy resins, Period. Polytech. Chem. Eng. 57 (2013) 85-91.

[17] B. Schartel, U. Braun, A.I. Balabanovich, J. Artner, M. Ciesielski, M. Döring, R.M. Perez, J.K.W. Sandler, V. Altstädt, Pyrolysis and fire behavior of epoxy systems containing a novel 9,10-dihydro-9-oxa-10-phosphaphenanthrene10-oxide-(DOPO)-based diamino hardener, Eur. Polym. J. 44 (3) (2008) 704-715.
[18] F. Laoutid, L. Bonnaud, M. Alexandre, J.M. Lopez-Cuesta, P. Dubois, New prospects in flame retardant polymer materials : from fundamentals to nanocomposites, Mater. Sci. Eng. 63 (3) (2009) 100-125.

[19] C. Huggett, Estimation of rate of heat release by means of oxygen consumption measurements, Fire Mater 4 (1980) 61-65.

[20] H. Nouailhas, C. Aouf, C. Le Guerneve, S. Caillol, B. Boutevin, H. Fulcrand Synthesis and properties of biobased epoxy resins. Part 1. Glycidylation of flavonoids by epichlorohydrin, J. Polym. Sci. Part A Polym. Chem. 49 (10) (2011) 2261-2270.

[21] K. Dai, L. Song, R.K.K. Yuen, S. Jiang, H. Pan, Y. Hu, Enhanced properties of the incorporation of a novel reactive phosphorus- and sulfur-containing flame retardant monomer into unsaturated polyester resin, Ind. Eng. Chem. Res. 51 (2012) 15918-15926.

[22] H. Takeuchi, K. Kitajima, Y. Yamamoto, K. Mizuno, Acid-base bifunctiona catalysis of proton-exchange X-type zeolite in ring opening of 1,2-epoxyalkanes by nucleophiles, Chem. Express 7 (1992) 613-616.

[23] M. Romdhani-Younes, M.M. Chaabouni, Efficient synthesis of $\beta$, $\beta^{\prime}$-dihydroxy sulfides by ring opening of epoxides with mercaptoethanol catalyzed under solvent-free conditions, J. Sulfur Chem. 33 (2012) 223-228.

[24] H. Lin, J. Ou, Z. Liu, H. Wang, J. Dong, H. Zou, Thiol-epoxy click polymerization fo preparation of polymeric monoliths with well-defined 3D framework for capillary liquid chromatography, Anal. Chem. 87 (2015) 3476-3483.

25] D. Guzman, X. Ramis, X. Fernandez-Francos, A. Serra, New catalysts for diglycidyl ether of bisphenol A curing based on thiol-epoxy click reaction, Eur. Polym. J. 59 (2014) 377-386.

[26] B. Boutevin, Y. Hervaud, G. Mouledous, N. Pelaprat, Synthesis of thiols bearing phosphonate groups, Phosphorus Sulfur Silicon Relat. Elem. 140 (1998) 125-133.

[27] L. Gonzales, F. Ferrando, X. Ramis, J.M. Salla, A. Mantecon, A. Serra, Charac terization of new reworkable thermosetting coatings obtained by cationic and anionic curing of DGEBA and some Meldrum acid derivatives, Prog. Org. Coat. 65 (2) (2009) 175-181.

[28] M. Bertoncini, J.C. Hoepfner, S.H. Pezzin, A novel route for the amidation of carbon nanotubes and their use as rein-forcement in epoxy matrix composites, Curr. Org. Chem. 17 (17) (2013) 1838-1843.

[29] S.V. Levchik, E.D. Weil, Flame retardancy of thermoplastic polyesters-a review of the recent literature, Polym. Int. 54 (2005) 11-35.

[30] D. Price, L.K. Cunliffe, K.J. Bullett, T.R. Hull, G.J. Milnes, J.R. Ebdon, B.J. Hunt P. Joseph, Thermal behaviour of covalently bonded phosphate and phosphonate flame retardant polystyrene systems, Polym. Degrad. Stab. 92 (6) (2007) $1101-1114$.

[31] H. Vahabi, C. Longuet, L. Ferry, G. David, J.J. Robin, J.M. Lopez-Cuesta, Effect of aminobisphosphonated copolymer on the thermal stability and flammability of poly(methylmethacrylate), Polym. Int. 61 (1) (2012) 129-134.

[32] R. Sonnier, B. Otazaghine, L. Ferry, J.M. Lopez-Cuesta, Study of the combustion efficiency of polymers using a pyrolysis-combustion flow calorimeter Combust. Flame 160 (10) (2013) 2182-2193.

[33] W.K. Patrick Lim, M. Mariatti, W.S. Chow, K.T. Mar, Effect of intumescent ammonium polyphosphate (APP) and melamine cyanurate (MC) on the properties of epoxy/glass fiber composites, Compos. Part B Eng. 43 (2) (2012) 124-128. 